Florida International University FIU Digital Commons

\title{
The Impact of Perceived Challenge and Hindrance Stress on Individual Well Being, Role Satisfaction, and Role Performance
}

Jason K. Steinert

Florida International University, jstei005@fiu.edu

DOI: $10.25148 /$ etd.FI1 1041505

Follow this and additional works at: https://digitalcommons.fiu.edu/etd

\section{Recommended Citation}

Steinert, Jason K., "The Impact of Perceived Challenge and Hindrance Stress on Individual Well Being, Role Satisfaction, and Role Performance" (2011). FIU Electronic Theses and Dissertations. 343.

https://digitalcommons.fiu.edu/etd/343 


\section{FLORIDA INTERNATIONAL UNIVERSITY}

Miami, Florida

THE IMPACT OF PERCEIVED CHALLENGE AND HINDRANCE STRESS ON

INDIVIDUAL WELL BEING, ROLE SATISFACTION, AND ROLE PERFORMANCE

A thesis submitted in partial fulfillment of the

requirements for the degree of

MASTER OF SCIENCE

in

PSYCHOLOGY

by

Jason Steinert 
To: Dean Kenneth Furton

College of Arts and Sciences

This thesis, written by Jason Steinert, and entitled The Impact of Perceived Challenge and Hindrance Stress on Individual Well Being, Role Satisfaction, and Role Performance, having been approved in respect to style and intellectual content, is referred to you for judgment.

We have read this thesis and recommend that it be approved.

Valentina Bruk-Lee

Daniel Wright

Jesse S. Michel, Major Professor

Date of Defense: January 24, 2011

The thesis of Jason Steinert is approved.

\begin{tabular}{r}
$\begin{array}{r}\text { Dean Kenneth Furton } \\
\text { College of Arts and Sciences }\end{array}$ \\
\hline Interim Dean Kevin O'Shea \\
University Graduate School
\end{tabular}

Florida International University, 2011 
C Copyright 2011 by Jason Steinert

All rights reserved. 


\section{DEDICATION}

I dedicate this thesis to my wife and to my two wonderful children. Without their unwavering patience, their constant support of my academic pursuits, and their unyielding love and understanding, the completion of my thesis would not have been possible. Also, to my mother, thank you for all of the sacrifice, without which I would not be in this position today. 


\section{ACKNOWLEDGMENTS}

I wish to thank the members of my committee for their constant support and patience throughout the entire process of my master's thesis. Each member of my committee provide me with their own unique and integral insights into the development and execution of this project. Dr. Bruk-Lee and her knowledge and experience with existing stress research was beneficial in my selection of scales best able to measure the variables I was considering. Dr. Wright and his statistical knowledge was essential in selecting and executing the analyses implemented in this study. Finally, I would like to thank my Major Advisor, Dr. Michel, whose guidance and support from inception to completion of this project has been constant and vital. Dr. Michel's knowledge of and

experience with the subject of my study has benefited me throughout every stage of my thesis. 


\begin{abstract}
OF THE THESIS
THE IMPACT OF PERCEIVED CHALLENGE AND HINDRANCE STRESS ON INDIVIDUAL WELL BEING, ROLE SATISFACTION, AND ROLE PERFORMANCE by Jason Steinert
\end{abstract}

Florida International University, 2011

Miami, Florida

\title{
Professor Jesse S. Michel, Major Professor
}

The current study considered school stress appraisal, as a challenge or hindrance, as it relates to individual school outcomes (performance and satisfaction), and individual health outcomes (physiological and psychological). Correlations were calculated between predictor and outcome variables. Confidence intervals were calculated and regression analyses performed in order to highlight differences in the relationship between predictors on the same outcome variables. A mediation analysis was conducted to establish the potential effect of health on the relationship between the predictors and performance/satisfaction outcomes. Challenge and hindrance stress were each found to be correlated with both types of health outcomes. Hindrance stress was found to be correlated with satisfaction. Challenge stress was found to be correlated with performance. Physical and psychological health were found to partially mediate the relationship between hindrance stress and satisfaction. Overall, stress appraisal was found to be a good predictor of individual outcomes. Health outcomes were found to mediate the relationship between satisfaction outcomes. 


\section{TABLE OF CONTENTS}

CHAPTER

PAGE

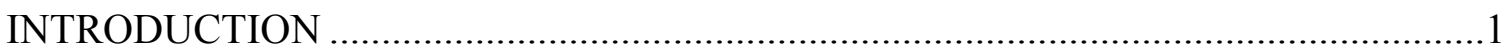

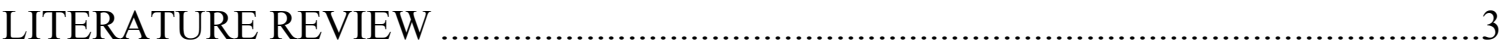

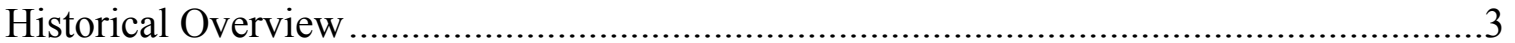

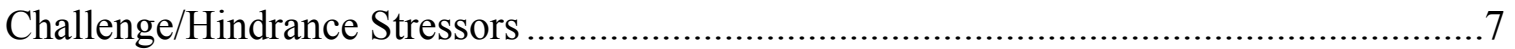

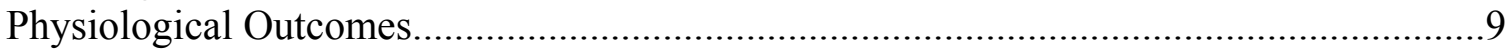

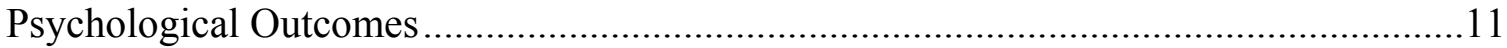

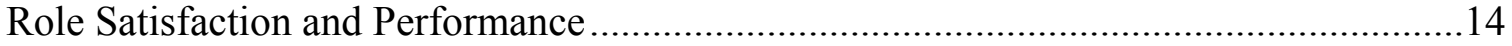

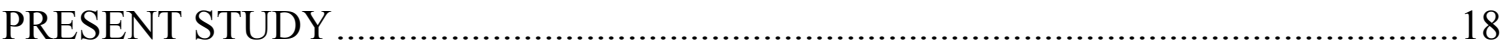

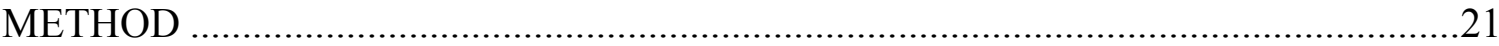

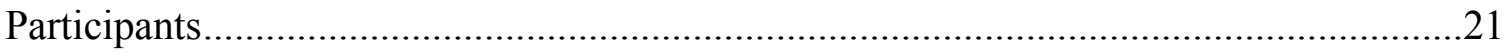

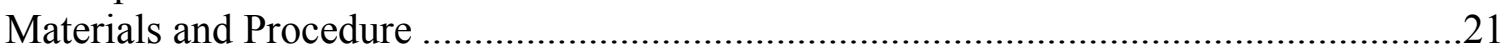

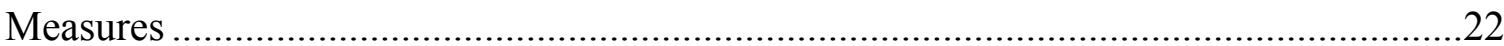

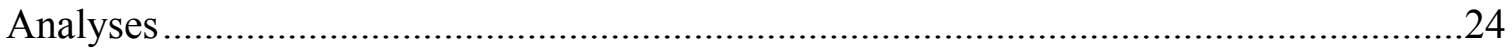

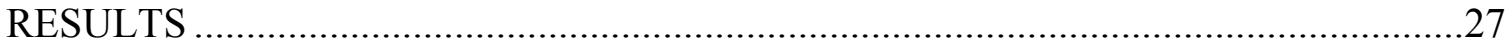

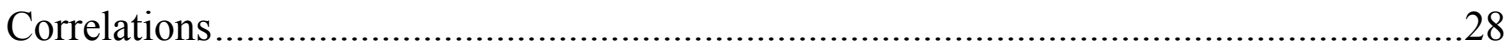

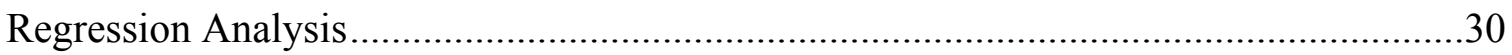

Mediation Analysis ...........................................................................................

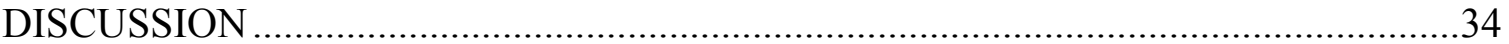

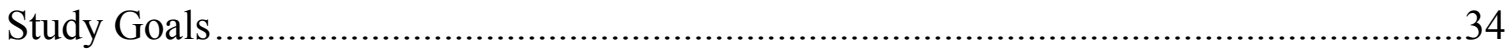

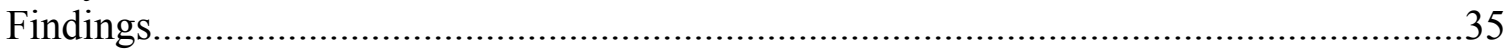

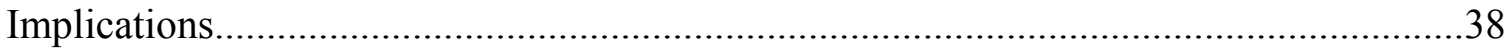

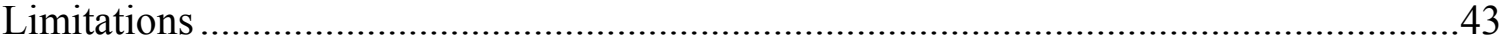

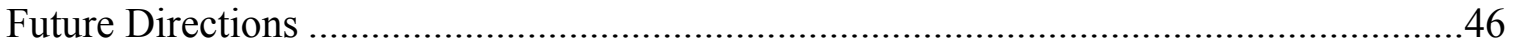

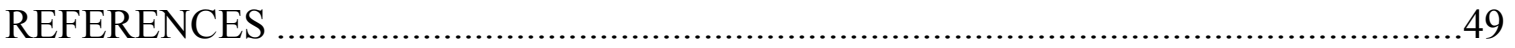

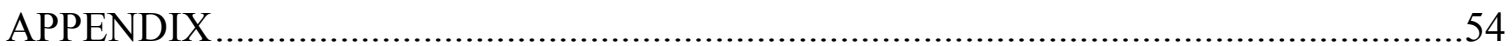




\section{LIST OF TABLES}

TABLE

PAGE

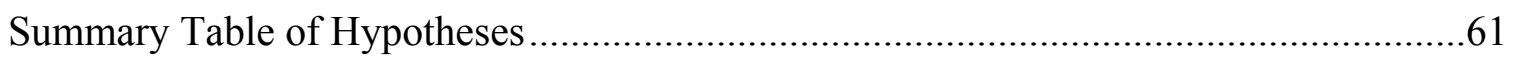

Sample size, Descriptive Statistics, Correlations, and Reliabilities of Study

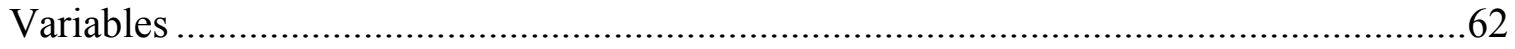

Correlations and t-values with Challenge and Hindrance Stress Predictors.......................63

Confidence Intervals with Challenge and Hindrance Stress Predictors

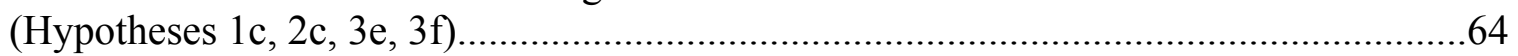

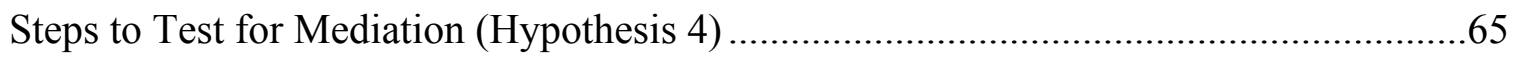

Mediated Regression Analyses for Challenge and Hindrance Stress on Performance, with

Health as the Mediator (Hypothesis 4) ......................................................................66

Mediated Regression Analyses for Challenge and Hindrance Stress on Satisfaction, with

Health as the Mediator (Hypothesis 4) ...........................................................................67 


\section{INTRODUCTION}

Existing research into the concept of stress has shed considerable light onto what stress is exactly, how it can manifest, and how an individual can cope with and even use stress to their benefit. The common assumption when considering the implications of stress on any individual is that negative outcomes will follow (DeLongis, Folkman, \& Lazarus, 1988). Research has shown, however, that this is not always the case, and that an individual experiencing stress can transform the stress reaction into a motivation to perform, i.e., a positive outcome (Cavanaugh, Boswell, Roehling, \& Boudreau 2000). Thus, the purpose of this study is to demonstrate how an individuals' experience of stress is linked to their appraisal of that stressor as a challenge or hindrance. In order to examine the link referenced above, this study will explore the relationship between the appraisal of a stressor and the development of associated stress related outcomes that manifest in individuals, both psychological and physiological stress outcomes. Additionally, this study will explore the relationship between the appraisal of a stressor and two salient outcomes, individual performance and satisfaction. Finally, this study will consider the mediating effect of health on individual performance and satisfaction.

In order to explore and develop this line of thinking further, it is first important to understand what stress is conceptually. Next, it is important to understand how stress can manifest in an individual. Finally, it is important to understand how those manifestations can impact individual school outcomes. In order to accomplish this, research will be reviewed that clearly demonstrates the implications of stress on organizational factors such as overall performance and attitudes (Raeve, Kant, Jamsem, Vasse, \& Van den 
Brandt, 2009), as well as research that considers the stress related health outcomes on individuals in a work/school context. Especially important in developing a framework for the current study will be use of the challenge/hindrance stress perspective offered by Cavanaugh et al. (2000). In this study, it was suggested that stress can be interpreted and utilized by an individual in both positive and negative ways. Further, it was proposed that individual variables such as affective state, motivation levels, and strain levels impact how an individual copes with and translates a stressor into a response. The suggested outcomes, which are contingent on the interpretation of the stressor, range from domain satisfaction and performance to individual well being, both physiological and psychological. However, for the purposes of this study, it is important to note that their relationships have only been suggested and never evaluated. Therefore, it is the goal of this study to fill this gap in the literature by illustrating that individuals appraise stressors in one of two ways, either as hindrance stressors, which are associated with varying levels of negative outcomes, or challenge stressors, which, while taxing on an individuals physiological and psychological faculties, do not generally result in significant negative outcomes. It is the hope of this author that these findings, should they illustrate the anticipated outcomes, will not only enhance the field and benefit the populations that we serve, but also generate further exploration into the area of stress appraisal, supporting the belief of this author, that stress can have both positive and negative outcomes which are dependent on a number of factors, beginning with the initial stress appraisal as a challenge or a hindrance. This body of knowledge will afford organizations insights into the origins of psychological stress responses such as anxiety, physiological stress reactions such as elevated blood pressure, as well as performance and satisfaction 
outcomes. This knowledge will prove essential in an organization's efforts to effectively understand and address workplace stress. My study will explore the interaction between individual responses to a series of scales designed to assess each of these dimensions, and will attempt to illustrate a relationship between type of stress appraisal and each of these suggested outcomes. First, a literature review of stress will be conducted to understand the existing research conceptualizations and frameworks applied to the field of stress research. Further, for the purposes of this study, the term stress will refer to stress, as it is the assertion of this author, after a review of the literature, that stress exists in multiple domains, and can be conceptualized in such a way that it can refer to the work of a student in an academic setting as readily as it can be used to refer to the work of an employee in an organizational setting.

\section{LITEATURE REVIEW}

\section{Historical Overview}

In Cannon's 1932 book titled "The Wisdom of the Body", Cannon refined the term homeostasis, which he first coined in 1914, and described it as the body's effort to restore a state of equilibrium whenever a deviation is required (i.e., a stress response). Seyle (1956), commonly known as the "father of stress" further developed this definition of stress when he proposed the 'general adaptive syndrome' by which individuals adapt to the challenges of everyday life by coping with situations that develop in and around them. There are three distinct phases in this process: Alarm, resistance, and exhaustion. The alarm phase is the point at which a person's physiological response begins. During the resistance phase, the body begins to recognize first, that all of its resources may not be necessary to respond to the situation. Finally, during the exhaustion phase, the body 
recognizes that its physiological resources have been depleted and makes a second attempt to gather its resources. It is important to note, that if this second attempt to mobilize fails, "disease of adaptation" can result, which essentially implies that there has been significant and often permanent impairment to the individuals physiological systems (Seyle, 1946). It is at this point when the individuals' physical and psychological resources have almost entirely been drained and a maladaptive response can result. Goeders (2003) further clarified this definition as it relates to the physiological response of an individual, stating that the:

Sympathetic nervous system responses include an increase in heart rate, a rise in blood pressure, a shift in blood flow to skeletal muscles, an increase in blood glucose, dilation of the pupils and a stimulation of respiration. Thus, the activation of the sympathetic nervous system results in a variety of physiological processes which prepare the organism for flight or fight, whether to face the stressor or attempt to escape it, to maintain homeostasis. (p. 435)

Additionally, according to Jex, Beehr, and Roberts (1992), work stress can further be conceptualized by considering its individual components of stimulus, response, stressor, and strain, which is typically known as the stimulus-response definition of stress. First, a stimulus is the stress associated with a force acting upon the individual (i.e., negative aspects of the work environment). Next, a response is the way an employee reacts to a stress-invoking situation. Thirdly, a stressor is some element of the work environment that requires an employee to respond in an adaptive manner. Finally, the last component, strain, is defined as the various maladaptive ways in which an employee responds to stressors. Strain can be further broken down into three types of perceived 
strain: psychological, physical, and behavioral. Spector, Dwyer, and Jex (1988) suggested that psychological stain can be defined by as an emotional responses or affective response, such as anxiety, hostility, frustration, depression. Ganster and Schaubroeck (1991) defined physical strain as a responses related to health and well-being, such as blood pressure and heart rate. In a meta analysis on organizational commitment by Mathieu and Zajac (1990), the authors offered that behavioral strain is commonly associated with noticeable impairments in job performance, such as absenteeism, turnover, and substance abuse. While receiving mixed support over the years, behavioral research by Cavanaugh, et al. (2000), on the impact of work stress has consistently shown support for the existence of a significantly positive relationship between stressors in the work environment, turnover intention and job search behaviors. Therefore, as indicated by Lepine, Lepine, \& Jackson (2004), it is feasible to assert that these two outcomes can be viewed in a student sample as stress in the academic context, thoughts of dropping out of school, and the desire to consider transferring to another area of study, or even, in the most extreme situations, the desire to consider alternate academic settings. The overall combination being the presence of stress, which is, according to Folkman (1984), can not be defined simply a property of the person or the environment alone, nor can it be conceptualized as a stimulus-response interaction, rather, in order to completely understand the concept of stress, one must consider the interaction between the person and the environment as a whole, and as a sum of each of the afore mentioned individual components of stress. Thus the process oriented concept of stress, which, as a part of the cognitive theory, suggests that the interaction between person and environment is constantly evolving, and the relationship is bidirectional, with person impacting the 
environment and environment impacting the person (Folkman, 1984).

Finally, Kahn, Wolfe, Quinn, Snoek, and Rosenthal (1964) offered an explanation of how work-related is most commonly experienced by an individual within the work environment, the concept of a role stressor. Such stressors are commonly associated with an employees' assigned role within an organization. Role stressors can surface in three major forms: Role ambiguity, role conflict, and role overload. Role ambiguity, as defined by Kahn et al. (1964), is experienced when an individuals' feels uncertain about their assigned role as a result of confusion about the conveyance of role-related information. Kahn et al. (1964) defined role conflict as experience by an individual when their is a lack of consistency in the role-related information provided to them on the job. Role conflict is typically associated with inconsistent information or conflicting demands. Finally, role overload, as defined by Kelloway and Barling (1991), is experienced by an individual when their employer demands more of then than that individual can accomplish in a give time-period, or with resources provided. Role overload is often accompanied by a perception of excess by the individual. Again, for the purposes of the student sample that will be used in this study, each of these three forms of role stressors are experience by students in an academic setting. Role ambiguity comes in the form of a student not necessarily understanding what is expected of them by their professors, advisors, courses, etc. Role conflict occurs in an academic setting when a student receives inconsistent information relating to assignments, examinations, etc., all of which has the potential to hinder the students ability to successfully manage their role as a student. Finally, role overload occurs in an academic setting when a student feels that the 
expectations of a professor, department, etc., are unrealistic and may not even be attainable.

\section{Challenge/Hindrance Stressors}

If one considers the implications of this existing knowledge base, especially the term 'homeostasis,' refined by Cannon (1932) in an effort to describe the body's effort to restore normalcy in the body whenever a deviation has occurred; the concept of the 'general adaptive syndrome,' as outlined by Seyle (1956) in an attempt to demonstrate that humans do many things in an effort to cope with challenge and maintain homeostasis; and the transactional theory of stress, as outlined by Lazarus (1966); it becomes clear that an individual has an automatic response to a stressful situation which begins with a consideration of the stressor (the appraisal), followed by a mobilization of response mechanisms/resources (the response), and finally an exhaustion phase which is the point at which the individual is no longer able to effectively manage the stressor (the outcome phase) (Pearsall, Ellis, \& Stein, 2009). The sum of the parts of this process being the ultimate goal of achieving a state of homeostasis where the individuals physical and psychological capacities are adequate in responding to and managing the stress without resulting in a maladaptive response. The challenge arises when considering how the process unfolds, from the first encounter with a stressor, to the individual response and ultimate outcomes. According to Cavanaugh et al. (2000), this process is comprised of two different types of individual responses to the stressor, the challenge response and the hindrance response. The challenge response is a constructive and positive response to a stress situation, usually resulting from exposure to stressors in the form of work time demands, hours, overtime, etc. Hindrance stressors are typically in the form of role 
stressors such as role conflict, role ambiguity, role overload, and various work constraints. The difference between the two is that hindrance stressors in the work setting are often the result of consistently undefined or unclear work role expectations or elements, whereas challenge stressors in the work setting, which can have a motivating effect, and are often perceived merely as inconveniences which may vary in their frequency, but are typically short lived (Cavanaugh et al., 2000). Further, in terms of their implications on work related outcomes, challenge stressors, with or without a motivating effect, can either enhance job performance and satisfaction, or have little to no altering impact on job performance or satisfaction outcomes. Such an absence of change, or change in the upward direction, has led researchers to label challenge stressors as positive in their appraisal and impact on the individual. Hindrance stressors, on the other hand, have been found to have a more significantly negative impact on job performance and satisfaction outcomes, with an often noticeable decrease in worker performance and reported satisfaction (Cavanaugh et al, 2000; Lepine et al., 2004).

In this same vain, Lemyre and Tessier (2003), the researchers responsible for developing the PSM-9 (Psychological Stress Measure), suggested that psychological stress can be experienced either as extreme (negative/hindrance) or energy boosting (positive/challenge), and that this interpretation of a stressor is a causal factor in the manifestation of physiological and psychological outcomes. Having established a framework for stress outcomes in the work environment, it is important to consider how the type of stress, i.e., challenge (positive) or hindrance (negative), may contribute to the development of psychological and physiological outcomes that may impact the overall well-being of an individual worker. Thus, when considering a stressor, which has 
typically been constrained by its association with negative outcomes, the distinction afforded to the classification of stress by the concepts of challenge and hindrance, has afforded stress researchers the opportunity to consider stress through a far broader perspective, one that does not limit the interpretation and understanding of stress to a set of negative outcomes, but, instead, opens up the possibility that stress, dependent on the individual and the situation, can and does have the potential for a positive impact on individuals. Further, for the purposes of this study, it is important to consider that the existing research into stress appraisal, as a challenge or hindrance stressor, has demonstrated that individuals can appraise an experienced stressor in a positive and productive manner (challenge) or in a negative and damaging (hindrance) manner (Cavanaugh et al., 2000). Thus, it is the aim of the present study to demonstrate that the manifestation and severity of these outcomes is partly contingent on the appraisal and magnitude of the experienced stressors.

\section{Physiological Outcomes}

According to Wright and Diamond (2006) "cardiovascular disease has severe consequences for both individual betterment and organizational health" (p. 395). Wright and Diamond (2006) further point out that more than 65 million Americans suffer from high blood pressure, and point out that if elevated blood pressure remains untreated, there is a marked increase in the likelihood of stroke, coronary heart disease, and kidney failure. Utilizing Cannon's definition of homeostasis, the authors proposed that the body responds to an environmental stressor as a means of achieving or maintaining a state of equilibrium (a state of optimal physical well-being). Thus, it can be inferred that with elevated stress levels on the job, an individual will work to maintain a state of 
physiological homeostasis. It can further be inferred that the individuals ability to accomplish this will depend on the severity of the stress situation as well as multiple physical and psychological factors ranging from presence of mental disorder, active substance abuse, pre-existing physical impairments, etc. (DSM-IV-TR, 2000).

DeLongis et al. (1988) proposed that there is in fact a significant relationship between stress experienced on a regular basis and the development of immediate and succeeding negative health outcomes ranging from sore throat, to headaches, backache, flu, etc. The findings of that study offered that stress can contribute to the development of both psychological and physiological outcomes, especially in individuals with low levels of social support. While social support is not of immediate importance for the purposes of the present study, the importance of this variable in assessing the development and subsequent magnitude of stress induced health outcomes, cannot be ignored. Spector and Jex (1998) further contributed to the area of stress and health with their creation of the PSI (Physical Symptoms Inventory). The PSI attempts to assess a relationship between the experience of stress and a range of maladaptive somatic physiological outcomes ranging from nausea to pain, and to ascertain whether the symptoms are significant enough to warrant medical attention.

Accordingly, when considering a challenge stressor, if an individual should appraise a stressor as a challenge, they are likely to experience a positive change in physiological outcomes. The following hypothesis, concerning this proposed relationship, has been offered.

Hypothesis 1a: Challenge stress is positively related to physiological health outcomes. 
The appraisal of a stressor as a hindrance has been suggested to yield a negative and potentially damaging reaction from the individual which can manifest in a variety of negative physiological outcomes (DeLongis et al., 1998). Thus, if an individual experiences a stressor as a hindrance, they are likely to experience a positive change in physiological outcomes. To summarize, the following hypothesis has been offered.

Hypothesis $1 \mathrm{~b}$ : Hindrance stress is positively related to physiological health outcomes.

Additionally, it appears that should the individual perceive a stressor to be a hindrance, the relationship between that stress appraisal and physiological outcomes will be stronger. The following hypothesis, concerning this proposed relationship, has been offered.

Hypothesis 1c: Hindrance stress is more strongly related to physiological outcomes than challenge stress.

\section{Psychological Outcomes}

According to Horowitz et al. (1979), the existing research into the psychological responses to stress commonly exhibited by individuals have offered two primary response sets: intrusion and avoidance. Intrusion can be conceptualized by considering its primary characteristics of undesirable mental pictures and thoughts, disturbing dreams, extreme emotional rises and drops, and obsessive/compulsive behaviors; i.e. psychological distress. Avoidance, on the other hand, can be conceptualized as refusal to accept realities of a situation, consequences of actions, various phobic responses to situational and environmental cues, etc. In other words, when considered together, the symptoms of intrusion and avoidance are indicative of existing depression and anxiety. 
Additionally, according to Raeve et al. (2009), "mental health problems are a major problem in the working population and are a leading cause of sickness absence and work disability" (p. 137). Raeve et al. (2009) proposed that several characteristics of the work environment may be responsible for the maladaptive responses of workers to workplace stressors, such as the context of the work situation that may include working time arrangements, psychosocial work characteristics, the presence of interpersonal conflicts, and job mobility. Further highlighting the importance of considering these relationships, the findings of Sanderson and Andrews (2006) have demonstrated that both social phobia and depression have been found to be the most prevalent disorders in the working population.

From the standpoint of individual performance, the relationships between stress and mental health have demonstrated that an individuals overall levels of performance will suffer as a result of these relationships. Contributing to this decrease in performance it can be expected that there will be a marked decrease in the cohesion of work groups, individual impairments on work task focus, fatigue, etc. These declines can be attributed to the symptomatology commonly associated with each of the mental and physical disorders explored thus far: i.e., fear/panic responses and avoident behaviors (anxiety disorders), sadness, anxiety (depression), impaired judgment, slowed work pace, distractibility, shortness of breath, frequent breaks, and increased fatigue (cardiovascular complications) (DSM-IV-TR, 2000). Further, according to the research of Stansfield (2008) it is the perceptions of job strain and associated job characteristics that can lead to social phobic reactions in the form of avoidance behaviors and fear of the workplace environment. If an individual is to exhibit anxiety disordered behaviors, such as panic 
attacks or agoraphobia, the impact on individual and organizational performance is obvious, with an expected reduction in overall performance levels.

In line with the existing research, if an individual should appraise a stressor as a challenge, they are likely to experience a positive change in psychological outcomes. To summarize, the following hypothesis has been offered.

Hypothesis 2a: Challenge stress is positively related to psychological health outcomes.

The appraisal of a stressor as a hindrance has been suggested to yield a negative and potentially damaging reaction from the individual which may manifest in a variety of negative psychological outcomes. For example, in the study conducted by Lepine et al. (2004), significant levels of interaction between emotional stability and stress appraisal were found. The findings of the Lepine, et. Al. (2004) study also suggested that should an individual perceive a stressor to be a hindrance, then they would experience an impairment in their emotional stability and thus exhaustion. In other words, when an individual experience a stressor that they perceive to be a hindrance, existing research has demonstrated a significant link between this appraisal type and psychological distress. Adding further support is the research of DeLongis et al. (1988), and Folkman and Lazarus (1986), both of which considered stress as it relates to negative psychological outcomes in the form of depression, mood disturbances, etc. Thus, should an individual experience a stressor as a hindrance, they are likely to experience a positive change in physiological outcomes. The following hypothesis, concerning this proposed relationship, has been offered. 
Hypothesis $2 \mathrm{~b}$ : Hindrance stress is positively related to psychological health outcomes.

Additionally, should the individual perceive a stressor to be a hindrance, the relationship between that stress appraisal and psychological outcomes will be stronger. To summarize, the following hypothesis has been offered.

Hypothesis 2c: Hindrance stress is more strongly related to psychological outcomes than challenge stress.

\section{Role Satisfaction and Performance}

In order to illustrate the proposed relationship between perceived stress and individual satisfaction and performance outcomes in the school domain, the existing research will examine the potential mediating role of health, both physiological and psychological. Lepine et al. (2004) took the first step at forming this linkage by suggesting a series of relationships, the first one being that there is a relationship between stress and exhaustion and that this relationship has an impact on one's ability to learn (e.g., school performance). Lepine et al. offered that there is a positive relationship between the appraisal of a stressor as a challenge and motivation to learn, a negative relationship between the appraisal of a stressor as a hindrance and motivation to learn, and an overall positive relationship between motivation to learn and learning performance. Thirdly, Lepine et al. also suggested that there is a negative relationship between the big five personality factor of emotional stability and exhaustion, with increases in exhaustion being associated with low emotional stability and a marked increase in irritability, tension, and anxiousness. Finally, Lepine et al. suggested that there is a positive relationship between emotional stability and motivation to learn and a 
positive relationship between emotional stability and learning performance. Overall, for the purposes of the current study, it can be inferred from these findings that there is a positive associations between appraisals of stress as they relate to exhaustion, motivation to learn, emotional stability, and learning performance; in other words, a stressor appraised as a challenge will contribute to a decrease in exhaustion, an increase in motivation to learn, an increase in emotional stability, and an increase in learning performance. More specifically, when considering emotional stability, this study will consider anxiety as a psychological function of these established relationship as opposed to the personality trait of emotional stability itself. Thus, it is important that the current study not only assess appraisal of a stressor as it relates to health outcomes, but what Lepine et al. (2004) has demonstrated to be an integral component of this relationship, the concept of performance.

Thus, when considering a challenge stressor, if an individual should appraise a stressor as a challenge, they are likely to experience an increase in school performance outcomes. The following hypothesis, concerning this proposed relationship, has been offered.

Hypothesis 3a: Challenge stress is positively related to school performance outcomes.

Accordingly, should an individual experience a stressor as a hindrance, they are likely to experience a negative change in school performance outcomes. To summarize, the following hypothesis has been offered.

Hypothesis $3 b$ : Hindrance stress is negatively related to school performance outcomes. 
Cavanaugh et al. (2000) considered the relationship between appraisal of a stressor as a challenge or hindrance and overall job satisfaction. This study demonstrated that an individual who appraises a stressor as a challenge is more likely to experience job satisfaction, as opposed to a stressor appraised as a hindrance contributing to lower levels of job satisfaction. Cavanaugh et al. (2000), drawing from the hassles and uplifts research of Lazarus (1981) and Lazarus and Folkman (1984), proposed that should an individual appraise a situation as an uplift, they are less likely to lead to health-related symptoms and enhanced coping, as opposed to a situation appraised as a hassle has a far greater likelihood of leading to the development of health-related symptoms and diminished coping. Hassles and uplifts can be viewed as being in a similar line with the concept of a stressor being appraised as a challenge or hindrance in that certain situations can enhance an individuals response whereas other situations can impair an individuals response. It is in this vain that Cavanaugh et al. (2000) demonstrated a positive link between stress and job satisfaction.

The existing research also successfully illustrates the relationships that exist between stress perceptions and reactions (i.e., the effect and orientations of both challenge stressors and hindrance stressors). Research by Podsakoff, LePine, and LePine (2007) highlighted that hindrance stressors had negative relationships with job satisfaction and organizational commitment and positive relationships with turnover intentions, actual turnover, and withdrawal behaviors. However, Podsakoff et al. (2007), showed that challenge stressors, on the other hand, demonstrated a positive relationships with job satisfaction and organizational commitment and negative relationships with turnover intentions and turnover. 
Thus, if an individual should appraise a stressor as a challenge, they are likely to experience a positive change in school satisfaction outcomes. The following hypothesis, concerning this proposed relationship, has been offered.

Hypothesis 3c: Challenge stress is positively related to school satisfaction outcomes.

Additionally, should an individual experience a stressor as a hindrance, they are likely to experience a negative change in school satisfaction outcomes. To summarize, the following hypothesis has been offered.

Hypothesis 3d: Hindrance stress is negatively related to school satisfaction outcomes.

Accordingly, if an individual perceives a stressor to be a hindrance, the relationship between that stress appraisal and performance/satisfaction outcomes will be stronger than the same relationship between a challenge stressor and school performance. The following hypotheses have been offered concerning this proposed relationship. Hypothesis 3e: Hindrance Stress is more strongly related to performance outcomes than challenge stress.

Hypothesis 3f: Hindrance Stress is more strongly related to satisfaction outcomes than challenge stress.

Finally, the existing research into individually experienced stress outcomes has clearly demonstrated a link between perceptions of stress and both performance and satisfaction in the school domain, as well as an inferential relationship between a multitude of physiological/psychological outcomes. These outcomes have been shown to manifest in a variety of maladaptive ways, all of which have a deleterious effect on both 
the individual and the organization to which they are affiliated. Research has consistently stated that there are multiple negative health outcomes which can result as the result of experiencing a stressor (Folkman \& Lazarus, 1986), and these outcomes are intensified or reduced/eliminated, depending on the individual appraisal of the severity and nature of the stressor; i.e., positive (challenge) or negative (hindrance) (Haar, 2006). Thus, it can, therefore, be inferred that the appraisal of a stressor as a challenge or hindrance and the manifestation of health outcomes will also contribute to the overall levels of satisfaction and overall performance level of an individual, i.e. a proposed mediating effect exists, with health outcomes acting as the mediator between the appraisal of the stressor and performance/satisfaction outcomes. Thus, one can assert that should an individual experience a challenge stressor, they are likely to experience negative health outcomes and therefore are also likely to exhibit negative overall school performance and negative overall reports of school satisfaction. Additionally, should an individual appraise a stressor as a hindrance, they are likely to exhibit negative overall school performance and negative overall reports of school satisfaction. To summarize, the following hypothesis has been offered.

Hypothesis 4: The relationship between challenge/hindrance stress appraisal and performance/satisfaction outcomes is mediated by both physiological and psychological health.

\section{PRESENT STUDY}

Overall it has been demonstrated from the defined relationships between stress, mental/physical health, and organizational outcomes (performance/satisfaction), that there is a potentially significant cost to both the individual and the organization. In light 
of the existing research, the goal of the present study is to not only highlight the significance of the relationship that exists between individual stress appraisal as a challenge or hindrance and the physiological and psychological outcomes, but also to demonstrate the impact of these proposed relationships on the individual and the organization, from the standpoint of performance and satisfaction outcomes. The current study will specifically explore the effects of stress appraisal on domain performance and satisfaction, mediated by individual well being. A central proposition of this study is the belief that the experience of stress is accompanied by an individual appraisal of the stressor as a challenge or hindrance, and a series of outcomes associated with this appraisal, either maladaptive, and manifesting in the form of negative physiological and psychological outcomes, or instead, with the individual exhibiting an adaptive coping response to the stressor and an avoidance of the development of negative physiological and psychological outcomes.

Figure 1: General Research Model

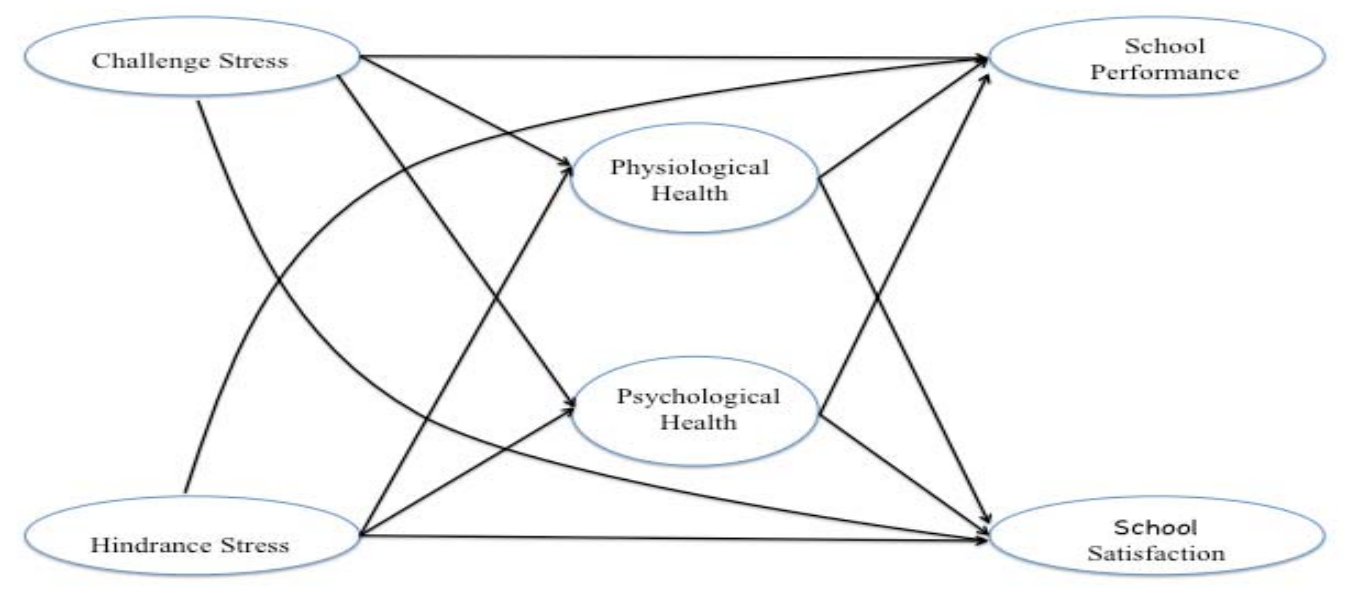


More specifically, it is the goal of this study to illustrate that individuals appraise stressors in one of two ways, either as hindrance stressors, which are associated with varying levels of negative outcomes, or challenge stressors, which, while taxing on an individuals physiological and psychological faculties, do not generally result in significant negative outcomes. It is the hope of this author that these findings, should they illustrate the anticipated outcomes, will not only enhance the field and benefit the populations that we serve, but also generate further exploration into the area of stress appraisal, supporting the belief of this author, that stress can have both positive and negative outcomes which are dependent on a number of factors, beginning with the initial stress appraisal as a challenge or a hindrance. A greater understanding of stress and stress type will afford organizations with insights into the origins of psychological stress responses such as anxiety, physiological stress reactions such as elevated blood pressure, as well as performance and satisfaction outcomes. Further, such insights into stress will prove essential in an organizations efforts to effectively understand and address workplace stress. The current study study will explore the interaction between individual responses to a series of scales designed to assess each of these dimensions, and will attempt to illustrate a relationship between type of stress appraisal and each of these suggested outcomes. For the purposes of the current study, stress will be measured through the responses of a student sample with scales that have been adapted to assess stress in the school domain. 


\section{METHOD}

\section{Participants}

The respondents sought for participation in this study were 538 undergraduate students, 18 years of age or older, and ranging from Freshman to Senior students in multiple undergraduate psychology classes at Florida International University. Students, who had the option to participate in research credits for class extra credit, enrolled in the study through the Florida International University SONA system; an online research system.

\section{Materials and Procedure}

Participants signed-in to access their SONA systems account and were redirected via a study link to the online survey materials. A brief description of the research project and directions outlining the process were provided. As a condition of participation, students were required to affirm that they were over the age of 18 . Participants completed survey items in two separate sessions: during the first session participants answered questing relating to demographic information, and the Challenge/Hindrance Scale; during the second session participants completed the SADS scale of psychological outcomes, the PSI scale of physiological outcomes scales, and two scales assessing school performance and satisfaction. Before both sessions, participants were provided with information pertaining to what the respective portion of the project entailed and were instructed to provide consent for participation electronically. Following the consent, participants indicated the degree to which each separate scale statement was true for them. (See appendix for exact scales and items). Once participants completed the scale portion of the 
survey on the first session, they were asked a series of demographic questions that include, age, gender, and ethnicity.

Participants were required to provide their student ID for the purposes of linking time one and time two data. Further, as a self-report performance measure, students were given the option to agree or disagree to their ID number being used for the purposes of GPA verification. To ensure confidentiality, at no point during the study were Panther ID numbers linked to any of the scales for individual analysis; rather, once the time one time two link was verified, and the applicable GPA data collected, Panther ID's were no longer used. GPA data was obtained from the Florida International University Department of Psychology Advising Department. Only aggregated group participant data were analyzed.

Participants were asked to sign-up through SONA systems for both the first and second session simultaneously. Within 48 hours of completing the first part of the study, participants received 1 SONA credit toward a psychology course. Exactly 14 days after completing part 1, participants were sent a link to part 2 of the study. Participants had no more than 7 days to complete part 2 of the study. Within 48 hours of completing part 2, participants received the second of 2 available credits for participation in this study.

\section{Measures}

Challenge/Hindrance Stress Levels (at school): Challenge/Hindrance stress levels were measured in Time-1 using an adapted version of the 10-item Stressor Scales (Lepine et al., 2004 from Cavanaugh et al., 2000). The adapted stressor scales instrument has demonstrated an overall Cronbach's alpha of .86 for the challenge items and .73 for the hindrance items (Lepine, et al., 2004). The stressors scale is a self report frequency 
measure designed to assesses individual perceptions of situations commonly associated with a stress reaction, ranging from time pressures, to overall responsibilities, to volumes of work, as either challenge or hindrance stressors. The aim of this scale is to assess how an individual both rates a stressor in terms of magnitude and appraises stressors as a challenge or as a hindrance. Participants responded to the statements and indicate frequency of stress on a Likert scale $(1=$ No stress to $5=$ A great deal of stress $)$ to each statement and indicate the level of stress each circumstance produces.

Psychological Outcomes: Psychological outcomes were measured at Time-2 using the 28-item Social Avoidance and Distress Scale (SADS) (Watson \& Friend, 1969). The SADS instrument has been valued at high reliability with its internal consistency at .94 and the test-reliability of .68 (Watson \& Friend, 1969). The SADS is a true or false self report social anxiety measure that taps into social avoidance and social distress among individuals in a variety of settings. Participants responded to the statements and indicate agreement using a true or false response.

Physiological Outcomes: Physical outcomes of stress were measured at Time-2 using the 18-item Physical Symptoms Inventory (PSI) (Spector \& Jex, 1998). The PSI is a self report frequency measure designed to assess general physical symptoms commonly associated with the experience of stress. Items include a variety of physical symptoms ranging from difficulty sleeping, backache, chest pain, etc. Participants responded to the statements and indicate frequency of symptomotology on a 5 point Likert scale $(1=$ No stress to $5=$ A great deal of stress).

School Performance: Performance in the school domain was measured at Time-2 using the 4-item School Performance Scale (Markel \& Frone, 1998). The School 
Performance Scale has demonstrated a Cronbach's alpha of .84 (Markel \& Frone, 1998).

The School Performance Scale is a self report frequency measures designed to assess an individuals overall performance in the school with items ranging from overall classroom effort to completion of assignments. Participants responded to statements and indicate levels of agreement on a 5 -point Likert scale $(1=$ Strongly Disagree to $5=$ Strongly Agree). As an additional measure of school performance, student ID numbers, when student permission is granted, were used to retrieve current overall student GPA's.

School Satisfaction: Satisfaction in the school domain were measured at Time-2 using the 6-item School Satisfaction Scale (Butler, 2007). The School Satisfaction Scale has demonstrated a Cronbach's alpha of .95 (Butler, 2007). The School Satisfaction Scale is a self report agreement measure designed to assess an individuals overall satisfaction with being a student, educational experience, and overall satisfaction with the university. Participants responded to statements and indicate levels of agreement on a 5-point Likert scale $(1=$ Strongly Disagree to $5=$ Strongly Agree $)$.

Analyses

Correlations between predictor and outcome variables were calculated to assess the proposed relationship between the appraisal of a stressor as a challenge or hindrance and two sets of individual outcomes, physiological/psychological outcomes and performance/satisfaction outcomes. In other words, the anticipated existence of health and performance/satisfaction outcomes was assessed as it relates to the appraisal of a stressor as a challenge or hindrance. Stress appraisals as they relate to health and performance/satisfaction outcomes are important relationships to highlight for the purposes of this study because the prediction is that changes in direction of a stressor will 
have an effect on health and performance/satisfaction outcomes. Further, in an effort to test the assertion that the relationship between hindrance stress and individual outcomes will be stronger than the relationship between challenge stress and the same outcomes, confidence intervals were calculated at both the $90 \%$ and $95 \%$ levels, and a t-test for dependent correlations was also performed.

Additionally, three separate post hoc regression analysis were used to examine the strength of the relationship between stress appraisal and health outcomes. The first regression analysis was used to illustrate which of the two proposed relationships (challenge and health outcomes or hindrance and health outcomes) was incrementally predictive of health outcomes above and beyond the other, which for the current study, has been proposed to be the relationship between hindrance stress and negative health outcomes. The second post hoc regression analysis was used to examine the significance of the relationship between stress appraisal and performance/satisfaction outcomes, and to illustrate which of the two proposed relationships (challenge and health outcomes or hindrance and health outcomes) was incrementally predictive of health outcomes above and beyond the other, which for the current study, has been proposed to be the relationship between hindrance stress and negative performance/satisfaction outcomes.

The third and final regression analysis was performed in order to assess the proposed relationship between the appraisal of a stressor as a challenge or hindrance, negative physiological/psychological health outcomes, and perceptions of satisfaction and performance. The benefit of using a regression analysis for the purposes of assessing these relationships is that it allows us to explicitly control for many other factors that simultaneously affect the dependent variable (Pedhazur, 1997). The relationship between 
stress, health, and performance/satisfaction is an important relationship to highlight for the purposes of this study because the predictions is that the existence of negative health factors (psychological and physiological) will mediate the relationship between stress appraisals (challenge and hindrance) and outcomes (performance and satisfaction). Thus, the presence of performance and satisfaction outcomes as they relate to an individual stress appraisal, will be impacted by the presence of negative health factors. According to general guidelines outlined by Kenny, Kashy, and Bolger (1998), there are four essential steps in illustrating the presence of a mediator (see also Baron \& Kenny, 1986; Judd \& Kenny, 1981; Shrout \& Bolger, 2002). The first step is to show that there is a significant correlation between stress $(\mathrm{X})$ and performance/satisfaction $(\mathrm{Y})$. The second step is to show that stress $(\mathrm{X})$ is related to negative health factors $(\mathrm{M})$, which is the mediating variable. The third step is to show that negative health factors (M) are related to performance/satisfaction outcomes $(\mathrm{Y})$, while stress $(\mathrm{X})$ is held constant. The final step is to test for complete mediation of stress and performance/satisfaction outcomes by the presence of negative health factors. In this step, the main goal is to try to demonstrate with the data that the multiple regression does not differ from zero. This step requires a comparison of regression values between those from step 1 and those from step 3 . When a mediating variable is present, the relationship between the variables in step $1(\mathrm{C}-\mathrm{P} ; \mathrm{H}-$ P; C-S; H-S) must be reduced (partial mediation) or eliminated (full mediation). To considering these relationships, eight separate multiple regression relationships were performed: challenge stress as it relates to performance, and the mediating effect of psychological health; challenge stress as it relates to performance and the mediating effect of physiological health; challenge stress as it relates to satisfaction, and the 
mediating effect of psychological health; challenge stress as it relates to satisfaction, and the mediating effect of physiological health; hindrance stress as it relates to performance, and the mediating effect of psychological health; hindrance stress as it relates to performance and the mediating effect of physiological health; hindrance stress as it relates to satisfaction, and the mediating effect of psychological health; hindrance stress as it relates to satisfaction, and the mediating effect of physiological health.

\section{RESULTS}

The following is a summary of the proposed and executed analyses for the present study: To test my assertion that a significant relationship exists between challenge and hindrance stress and multiple performance/satisfaction and health outcomes, an assertion which has been proposed in the literature by Lepine et al. (2004), I first calculated the correlations between proposed predictor (challenge and hindrance), and outcome variables (SADS, PSI, School SAT, School Performance, and GPA) using SPSS 18. Additionally, to test the assertion that the relationship between hindrance stress and individual outcomes will be stronger than the relationship between challenge stress and the same outcomes, confidence intervals were calculated at both the $90 \%$ and $95 \%$ levels. As sufficient support was not provided by a comparison of correlations alone, or through a comparison of CI between the correlational variables, further analysis was performed using a post hoc regression analyses to determine if the dependent variable (hindrance stress) was incrementally predictive above and beyond the other dependent variable (challenge stress). Finally, to test my second assertion that a mediating relationship exists between Challenge/Hindrance stress and Performance/Satisfaction outcomes, with Psychological/Physiological Health outcomes as the mediator, I used the Baron and 
Kenny's (1986) model of testing mediation. It is important to note, that while I did consider self report performance as a possible variable in the mediation relationship, GPA was also used in order to offer a more robust analysis, especially as self report performance measures have come under fire due to their reported fake-ability and lower reliability (Cronbach, 1970).

\section{Correlations}

Table 2 shows descriptive statistics, internal consistency reliabilities, and correlations among all study variables. As expected, support was provided for Hypothesis 1a $(\mathrm{r}=.18, \mathrm{p}<.01)$, which states "Challenge stress is positively related to physiological health outcomes (IV=Challenge Stress; DV=PSI).” Therefore, as there is a positive change in hindrance stress in the school domain, there is also a positive change in physiological health outcomes. Hindrance stress was found to be highly correlated with satisfaction physiological health outcomes, providing support for Hypothesis $1 \mathrm{~b}(\mathrm{r}=.26$, $\mathrm{p}<.01)$. Therefore, as there is a positive change in hindrance stress in the school domain, there will also be a positive change in physiological health outcomes. Challenge stress was positively related to psychological health outcomes, in support of hypothesis $2 \mathrm{a}(\mathrm{r}=$ $.18, \mathrm{p}<.01$. Therefore, as there is a positive change in hindrance stress in the school domain, there will also be a positive change in psychological health outcomes. Further, support was found for Hypothesis $2 \mathrm{~b}(\mathrm{r}=.22, \mathrm{p}<.01)$, which states "Hindrance stress is positively related to psychological health outcomes." Therefore, as there is a positive change in hindrance stress in the school domain, there will also be a positive change in psychological health outcomes. Challenge stress was also found to be correlated with performance in the school domain, thus providing partial support for Hypothesis $3 \mathrm{a}(\mathrm{r}=$ 
$.09, \mathrm{p}<.05)$. Therefore, as there is a positive change in challenge stress in the school domain, there will also be a positive change in school performance outcomes. Hindrance stress was found to be highly correlated with satisfaction in the school domain, providing support for Hypothesis $3 \mathrm{~d}(\mathrm{r}=-.13, \mathrm{p}<.01)$. Therefore, as there is a negative change in hindrance stress in the school domain, there will be a positive change in school satisfaction outcomes.

Hypotheses 3a (with GPA as the school performance measure), 3b (with both self-report performance and GPA as the school performance measures), and 3e (with both self-report performance and GPA as the school performance measures) received no support. Thus, when considering stress perceptions as they relate to school performance, the results demonstrate that while challenge stress is related to school performance, the relationship only exists when considering a self-report measure of performance. Further, when considering a hindrance stressor, the results indicate that there is no correlation between perception of stress and either of the two measures of school performance. Hypothesis $3 \mathrm{c}$ also received no support from the results, finding no correlation between challenge stress and school satisfaction.

Finally, when considering hypotheses $1 \mathrm{c}, 2 \mathrm{c}, 3 \mathrm{e}$, and 3f, an initial comparison of correlations between hindrance stress and individual outcomes with challenge stress and the same individual outcomes, did appear to support the hypotheses that hindrance stress would have a stronger relationship with individual outcomes than would challenge stress. However, a more thorough analysis of the above relationships, using confidence intervals at both the $90 \%$ and $95 \%$ levels, failed to provide adequate support for any strength difference between hindrance and challenge stress as predictors of individual outcomes, 
with overlapping confidence intervals (see Table 4). This will be discussed in greater detail in the discussion section. Additionally, a t-test for dependent correlations was also performed to test the same hypotheses. However, as shown in table 3 , there is no support for the hypotheses $1 \mathrm{c}, 2 \mathrm{c}, 3 \mathrm{e}$, and $3 \mathrm{f}$, which predicted that hindrance stress would be more strongly correlated with the individual outcomes than would challenge stress.

\section{Regression Analysis}

A final attempt to uncover any differences that may exist between the strength of hindrance stress and challenge stress as predictors of individual outcomes was made with post hoc regression analyses. Hypothesis 1c, which states "Hindrance stress is more strongly related to physiological outcomes than challenge stress," received support (Challenge: $\beta=.18$; Hindrance: $\beta=.26$ ) but not in terms of the strength of the relationship. Rather the analysis demonstrated that hindrance stress is incrementally predictive of physiological health outcomes above and beyond challenge stress. Therefore, a positive change in hindrance stress in the school domain will yield a positive change in physiological health outcomes in the same domain; whereas a challenge stress, while also demonstrating a concurrent change in stress and physiological health, does not appear to be as predictive of health outcomes as hindrance stress.

Similar to Hypothesis 1c, Hypothesis 2c, which states "Hindrance stress is more strongly related to psychological outcomes than challenge stress," also received support (Challenge: $\beta=.18$; Hindrance: $\beta=.22$ ), but, again, not in terms of the strength of the relationship. Rather the regression analysis demonstrated that a positive change in hindrance stress in the school domain will yield a positive change in psychological health outcomes in the same domain, with challenge stress appearing to be a less likely predictor 
of the same psychological health outcomes.

Finally, there was also support for Hypothesis $3 f$ (Challenge: $\beta=-.04$; Hindrance: $\beta=-.13$ ), which states "Hindrance Stress is more strongly related to satisfaction outcomes than challenge stress." However, once again, the strength of the relationship was not supported, rather the support was for the predictive ability of hindrance stress above and beyond that of challenge stress, when considering school satisfaction outcomes. Further, it is important to note that challenge stress was not found to be significantly related to school satisfaction. Therefore, while a positive change in both challenge and hindrance stress in the school domain will yield a positive change in school satisfaction outcomes in the same domain, hindrance stress appears to be more predictive of school satisfaction outcomes than does challenge stress.

\section{Mediation Analysis}

In order to test the mediating effects of psychological/physiological health mediators on the relationship between challenge/hindrance stress appraisal and performance/satisfaction outcomes, which was proposed in Hypothesis 4, the Berry and Kenny (1986) method was used (see Table 5). Hypothesis 4, which states "The relationship between challenge/hindrance stress appraisal and performance/satisfaction outcomes is mediated by both physiological and psychological health," proposed that the effects of a challenge and hindrance stressor on school performance and satisfaction, would be mediated by psychological and physiological health factors. As described by Baron and Kenny (1986), there are several steps necessary to demonstrate mediation. The first step is to demonstrate that the independent variable (challenge/hindrance stress) must significantly predict the dependent variable (performance/satisfaction). As shown 
above in the test of hypothesis 3a, individuals reporting positive challenge stress also reported positive self-report school performance $(\beta=.09)$. Individuals reporting negative hindrance stress, reported positive school satisfaction, in support of hypothesis $3 b$ ( $\beta=-$ .13) (see Table 9).

The second step of the Baron \& Kenny (1986) method is to demonstrate that the independent variable (challenge/hindrance stress) must significantly predict the mediator variables (psychological/physiological health factors) (see Table 5). As shown above in our test of hypothesis 1a, individuals reporting positive challenge stress also reported a positive change in physiological health $(\beta=.18)$. Hypothesis $1 \mathrm{~b}$ showed that individuals reporting positive hindrance stress also reported a positive change in physiological health outcomes $(\beta=.26)$. Further, as shown above in our test of hypothesis $2 \mathrm{a}$, individuals reporting positive challenge stress also reported a positive change in psychological health factors $(\beta=.18)$. Hypothesis $2 \mathrm{~b}$ showed that individuals reporting positive hindrance stress also reported a positive change in psychological health outcomes $(\beta=.22)$ (see Table 7).

The third step of the Baron and Kenny (1986) method is to demonstrate that in the presence of the mediating variable/s (physiological/psychological health factors), the relationship between the independent (challenge/hindrance stress) and dependent variables (performance/satisfaction) must become significantly reduced (see Table 5). Partial mediation was found to exist between hindrance stress and school satisfaction when the relationship was mediated by physiological health factors. Hindrance stress was found to be significant at the .05 level and positively related to school satisfaction outcomes $(\beta=-.10, p<.05)$ in the presence of physiological health factors. In other 
words, the relationship between hindrance stress and school satisfaction is partially mediated by psychological health factors (see Table 9). The mediation analysis also showed support for a second partially mediated relationship between hindrance stress and school satisfaction when the relationship was mediated by psychological health factors. As hindrance stress was found to be significant at the .05 level and negatively related to school satisfaction outcomes $(\beta=-.10, p<.05)$, it can be inferred that the relationship between hindrance stress and school satisfaction is partially mediated by psychological health factors (see Table 9). Therefore, the significance of the relationship between hindrance stress and school satisfaction is affected when partially mediated by psychological health factors. For each of the partial mediation relationships: hindrance with satisfaction, mediated by physiological health factors; and hindrance with satisfaction, mediated by psychological health factors; the values from Table 7 illustrate that the $\beta$ value ( $\beta=-.10$ ) calculated from step 4 (which is the same for physiological health and psychological health factors) has in fact been reduced when compared to the $\beta$ value ( $\beta=-.13)$ calculated in step 1 of the Barron and Kenny (1986) method. Thus, the requirements for partial mediation have been met, and the conclusion can be drawn that both physiological and psychological health factors partially mediate the relationship between hindrance stress and school satisfaction outcomes (see Table 9).

However, when considering the additional mediation relationships proposed in this study: challenge stress and school performance, mediated by physiological/psychological health factors, challenge stress and school satisfaction, mediated by physiological/psychological health factors, and hindrance stress and school performance, mediated by physiological/psychological health factors, the results do not 
offer support for the hypotheses, with the calculated $\beta$ values for each in step 4 being neither reduced nor eliminated when compared to the calculated $\beta$ values from step 1 (see Table 9).

\section{DISCUSSION}

\section{Study Goals}

The goals of the present study were to consider the existence of the hypothesized relationships between challenge/hindrance stress and four types of anticipated individual outcomes, ranging from physiological health outcomes, to psychological health outcomes, to school performance outcomes, and finally, school satisfaction outcomes. Research has shown that stress, as an overarching construct, has an effect on each of these outcomes (Folkman et al., 1986; Cavanaugh, et al., 2000), however, current efforts have not examined the impact of different types of stress, namely challenge (commonly thought to be a positive stress type) and hindrance stress (commonly thought to be a negative stress type), on the same outcomes. It was the aim of this study to consider such relationships in hopes of understanding individual stress at a more finite level, with individual appraisal of a stressor as the focal point of these proposed relationships. Additionally, a separate goal of the present study was to consider whether the presence of stress related health, both physiological and psychological, would have any impact on individual school domain performance and or satisfaction outcomes. In other words, would the existence of such health factors, mediate the relationship between stress type and performance/satisfaction outcomes, suggesting that relationship between stress and performance/satisfaction outcomes can not be examined alone, and must be examined with a consideration of the existence of health factors. 


\section{Findings}

As both challenge stress appraisals, which can be thought of a the amount of time one spends working on a classroom assignment, and hindrance stress appraisals, which can be though of as the inability to clearly understand what is expected of you in your classes, were found to have a high positive correlation with both physiological and psychological health outcomes, it can be inferred that students in the school domain who experience either type of stress are also likely to experience negative health outcomes. From the physiological standpoint, these outcomes may occur in the form of increased frequency or severity of headaches, back pain, etc. From the psychological standpoint, these outcomes may occur in the form of increased anxiety levels, feelings of depression, etc.

Further, as the findings demonstrated that challenge stress was found to have a positive correlation with self report performance in the school domain, it can be expected that students who experience a challenge stressor are likely to report an increase in performance that could translate into a variety of academic improvements ranging from improved attendance rates to higher exam scores, etc. However, as there was no support for the relationship between GPA as a performance measure and challenge stress, it is important to consider that performance may only be partially correlated with school performance, and that the anticipate improvement in performance may not be as notable as the results might suggest from the self report performance/challenge stress correlation. Additionally, as the relationship between hindrance stress and GPA was also insignificant, the power of the sample size is called into question as a possible cause of these findings. See the limitations section for additional explanations. 
Additionally, on the basis of the examination of the relationship between hindrance stress and school satisfaction, which demonstrated that a negative correlation exists between hindrance stress and satisfaction in the school domain, it is likely that students who experience a decrease in hindrance stressors will experience an increase in the occurrence of individual school satisfaction outcomes ranging from an overall better attitude in the student to a willingness to participate more openly or with greater frequency. These students are likely to report that as their "negative" stress level decreases, they are able to become more satisfied with their school environment and therefore more active within that same environment. However, when considering the relationship between a challenge stressor and school satisfaction, the findings showed that challenge stress is not correlated with satisfaction in the school domain, suggesting that a student who experiences a challenge stressor will not experience any change in their satisfaction. The finding that challenge stress is not correlated with school satisfaction makes sense in that a student experiencing a challenge stressor, which is considered positive in nature, should not experience any improvement or loss of satisfaction as a stressor inherently demands an individual response (Lazarus, 1966), in an effort to manage it's impact, but does not require an individual to exhaust their resources in order to cope with the effects of the stressor. In other words, no matter what type of stressor an individual encounters, that individual will need to respond to the stressor. It is the nature of this response that characterizes the magnitude and direction of the relationship between a challenge/hindrance stressor and satisfaction outcomes, with a challenge stressor causing the individual to experience less strain than would a hindrance 
stressor, and therefore the same individual experiences little to no significant change in their domain satisfaction (Seyle, 1956 \& Cannon, 1932).

Additionally, it is important to note that while the findings did not support the four hypotheses which stated that hindrance stress would be more strongly related to individual outcomes than would challenge stress, a post hoc analysis with regression demonstrated that hindrance stress was, however, incrementally predictive of individual school performance and satisfaction outcomes above and beyond challenge stress.

Finally, the finding of the partial mediation of hindrance stress and school satisfaction by physiological health outcomes seems to suggests that as there is a negative change in hindrance stress in the school domain, there will be a positive change in school satisfaction outcomes, which will be partially mediated by physiological health outcomes. Therefore, in the presence of the mediating variable (physiological health), the relationship between hindrance and satisfaction was reduced, with a change in $\beta$ of -.03 . Further, the finding of the partial mediation of hindrance stress and school satisfaction by psychological health outcomes seems to suggest that as there is a negative change in hindrance stress in the school domain, there will be a positive change in school satisfaction outcomes, which is partially mediated by psychological health outcomes. Therefore, the relationship between hindrance and satisfaction, in the presence of the mediating variable (psychological health), was reduced, with a change in $\beta$ of -.03 . Overall, it is important to consider that when considering partial mediation as opposed to full mediation, the relationship between the IV and the DV will continue to exist, in a reduced state, even in the presence of a mediating variable. In other words, hindrance stress is related to satisfaction on it's own, but it is also related to satisfaction when 
taking the presence of health factors into account, with the mediating relationship between hindrance stress and satisfaction affected partially when going through the health outcomes. Full mediation, on the other hand, suggests that the relationship between the IV and the DV cannot exist without the mediating variable. In other words, with full mediation, the relationship between hindrance stress and satisfaction cannot exist without considering the presence of health factors.

\section{Implications}

The findings of the study have clearly demonstrated a link between both challenge and hindrance stress and a variety of individual outcomes. However it is also important to consider the possible implications of these relationships on the organizational setting. The first of these relationships occurred between both challenge and hindrance stress and physiological health outcomes. From the standpoint of an organization, for the purposes of this study, an academic organization, knowledge of the potential consequences of stress type and magnitude may translate into greater levels of sensitivity among educators towards students who may exhibit these physiological responses to stress. Increased sensitivity could translate into the development of accommodations aimed at reducing the stressor and or responding to the physical needs of students. Stress reduction can occur when an educator designs assignments to be challenging yet manageable to the majority of students. Responding to physical needs could be in the form of less restrictive policies regarding excused absences, i.e. not placing a limit as long as adequate evidence is provided, or, this could be in the form of utilizing classroom technologies such as power point slides provided to students prior to class, or video lectures, both of which can be posted on line, etc. 
The next of these relationships occurred between both challenge and hindrance stress and psychological health outcomes. In an academic setting the implications of these interaction are significant in that educators who possess knowledge of certain stress related psychological pathologies can learn how to more effectively manage and respond to the psychological limitations that students may have or may develop as a result of academic/work expectations. It is important to note, that while it is likely that nearly all students experience stress related academic anxieties, those anxieties may manifest differently across students. Thus, much like with physical outcomes, increasing the sensitivity of educators will allow them to develop classroom procedures designed to reduce overall psychological stress, i.e. anxiety, while also responding to the individual psychological needs of students. Such procedural modifications could be in the form of offering students a choice between in-class or take-home examinations, the use of openended exam questions, substantial extra-credit opportunity, fewer lectures and more hands on experiences, group work as opposed to individual based assignments, and classroom breaks. Educators could also implement classroom policies designed to illustrate sensitivity to individual student needs, in the form of extra office hours, icebreaking activities designed to lessen feelings of apprehension which will demonstrate that all students and educators share certain academic anxieties, and support policies designed to add extra help/support to students when needed. While it is likely that some of the above referenced procedural measures may be implemented by educators, the insights provided by the findings of this study will afford educators with increased awareness into the importance of fully integrating sensitivity procedures, perhaps at the university level. 
The next set of relationships occurred between both challenge stress individual performance outcomes. In an academic setting the implications of these interaction are significant in that educators can become more aware of the importance creating an academic environment for students that stems from clearly designated standards and expectations. Educators with insight into the link between challenge stress appraisal and improved performance can implement syllabi with clearly detailed descriptions of assignments, deadlines, and expectations of students. Further, classroom assignments/activities can be both difficult and challenging to students in so far as they are reasonably developed and delivered. Much like with the relationship between challenge stress and health outcomes, the provision of accommodations such as defined extra office hours and fairly developed classroom policies that are sensitive to the needs of both individual students and the class as a whole, will act as a motivator to students and may improve their performance in the classroom (Hackman \& Oldham, 1976).

The next of these relationships occurred between both challenge and hindrance stress and individual satisfaction outcomes. From an academic standpoint, the implications of these findings are many, but most specifically related to the discovery that to eliminate or lessen hindrance stress is to improve the satisfaction of a student. Thus, in order to accomplish this, it is in the best interest of an educator to remove ambiguity from their classroom design. Much like a reverse of the relationship between challenge stress and performance outcomes, where the focus was on providing students with clarity, guidance, and support, the present relationship would suggest that the same provision to students is attainable so long as an educator is able to eliminate class elements that are confusing and or unrealistically demanding of their students. Educators may work to 
redesign a syllabus that is unclear; they may eliminate assignments that are unfair or not in line with students ability levels, etc., all, with the main goal of being sensitive to the individual differences/needs of students in an effort to improve their satisfaction and ultimately, their performance in the classroom. Especially important in this relationship is the inference, supported by existing research (Judge, Thoreson, Bono, \& Patton, 2001), that there may be a direct link between satisfaction and performance, suggesting that an increase in one will lead to and increase in the other, and vise versus.

Additionally, the finding that hindrance stress is incrementally predictive of individual health and performance/satisfaction outcomes above and beyond challenge stress, suggests that within an academic setting it is in the best interest of an educator to design the class environment in such a way so as to enhance the presence of challenge stressors. Adding further supporting these results are the findings of Lepine, et al. (2004), which suggest that a challenge stressors, which can have a motivating effect on students, are preferential, as opposed to hindrance stressors, which, as research suggests (Cavanaugh, et al., 2000), have a motivation depleting effect on individuals.

Finally, the finding that the relationship between a hindrance stress appraisal and satisfaction is partially mediated by both physiological and psychological health factors, is important in an academic setting because it demonstrates to educators that these relationships may not be entirely stand alone, and that other factors, in the case of this study, health, may play a role in the relationship between predictor and outcome variables, i.e., stress and satisfaction outcomes. Thus, educators may be able to more clearly understand the cause and effect of certain relationships, and may be able to work around or with factors that have the potential to exacerbate a relationship between 
hindrance stress appraisal and satisfaction. In other words, with provisions aimed at addressing the physical and psychological needs of students, such as those discussed above, educators may be able to have a positive impact on the relationship that already exists between hindrance stress and satisfaction.

Overall, the findings demonstrate that there is a fine line between a stressor that has the capacity to motivate an individual and one that has the ability to hinder an individual. However, the findings also seem to illustrate that the same fine line also exists when considering a challenge stressor on its own. Thus, when considering a challenge stressor it is important to both consider the level of the individual stressor as well as the individual experiencing the stressor. A consideration of the individual stressor will allow for greater control over whether a challenge stressor will in fact have the intended outcome, that of motivation, as opposed to the outcome on the other side of the line, which more closely resembles that of a hindrance stressor. Therefore, within the academic settings, where it is the professor who is primarily responsible for setting the tone of classroom expectation for students, assignments should be designed so as to achieve the highest levels of motivation, while not crossing the fine line that separates a motivating stressor from a motivation depleting stressor. Additionally, it is important to consider that every individual may not respond in the same way to a given stressor. In other words, a stressor designed as a challenge, and appraised by some individuals in a class as such, may in fact be appraised by others as a hindrance. Thus, individual differences such as pre-existing health conditions, personality type, pre-existing stress levels, etc., may impact an individuals appraisal of a stressor. In order to avoid this, it is important for a professor to consider the global need of a class, while also maintaining a 
sensitivity to the respective needs of individuals within the class.

\section{Limitations}

It is my impression that in order to completely understand whether a difference does exist between challenge and hindrance stress, it would be necessary to understand not only the existence of a relationship between the stressor and expected outcomes, as this study considered, but also the magnitude of the individual stressors as they relate to the anticipated outcomes. In other words, as the magnitude of the stressor perceived to be a challenge/hindrance increases or decreases, is there is a respective increase or decrease in individual outcomes? If this were the case, then these findings would appear to support the assertions of previous researchers such as Lepine, et al. (2004) and Cavanaugh, et al. (2000), who each suggested that stress type will in fact influence outcomes. However, the question remains as to how does one define stress type. Is type related to the magnitude of a stressor, the directionality (positive or negative), or is it more specifically a contextual issue that can be divided into specific categories of stress? Along these same lines, is a challenge/hindrance stress of low magnitude likely to yield the same positive/negative outcomes as a challenge/hindrance stressor of high magnitude? According to the research of Cavanaugh, et al. (2000) and Lepine, et al. (2004), it seems more likely that negative outcomes would be related to a hindrance stressor than to a challenge stressor. Therefore there seems to be some clarity on the question of directionality. However the question of magnitude remains for future research studies to examine.

Further, as second possible limitation of the present study, it is important to consider the high correlation of .71 between challenge and hindrance stress type. This 
result, which is contrary to the .40 correlation offered by Lepine, et al. (2004), suggests that challenge and hindrance stress may be too related to offer them as two separate stress types. Thus, when considering the results of the present study, the high correlations between stress type and outcomes may be more a matter of overall stress leading to individual outcomes, rather than stress type contributing to individual outcomes.

Additionally, as a third potential limitation of the present study, when considering that participation in this study, for many students, was motivated in part by a desire to be awarded class credit, it can be inferred that the quality of participation may have been contingent on the perception of reward, the students individual class preferences, i.e., did they like or dislike the class, perceptions of how burdensome the task of participating would be, etc. These factors may have led to the presence of faking which would suggest that a participant may not give an accurate report of their performance when responding to self-report performance related items (Cronbach, 1970).

A fourth limitation of the present study relates to the finding that hindrance stress was not related to individual performance outcomes. One possible reason for this finding is related to errors associated with the faking because of social desirability effects of self report data (Cronbach, 1970). Thus, when considering a self report of performance in the school domain, it may be fair to assume that students may have faked their responses to survey items because of a desire to appear as higher performers than they actually are, thus, as a result, impacting the study findings.

A fifth limitation of the present study were the findings relating to the nature of the GPA variable. Grade point average (GPA), which is an objective measure of school performance, was utilized in this study, in addition to the self-report performance 
measure, to assure that an accurate analysis of performance was obtained. However, GPA was unexpectedly found to have no significant relationship with either of the stress appraisals, challenge or hindrance. Thus, stress type was found to be unrelated to GPA. One of the reasons for this may have been that GPA is a cumulative and global measure of academic performance, and may not be reflective of a student's perception of their overall performance (Organ, 1988). For example, a student may consider their academic performance as just one piece of a larger picture of their performance that may include employment and family responsibilities, in addition to academic work. As the sample was drawn from a large urban university with a large population of working students, the importance placed on academic performance may vary considerably from student to student depending on their life situations. For some students, academic work, while necessary and important, may simply be a means of securing a higher paying job, which would be determined more by the attainment of a degree and less on GPA. Therefore, these students would likely measure performance derived from degree progress and less on GPA. Alternatively, the research of Berry and Sackett (2009) suggests that GPA may not be as strong a predictor or performance as previously thought especially when considering other factors directly related to but outside of GPA, i.e., difficulty of classes. In other words, a student may, in general be a high performer in most of their classes, yet their poor performance in an especially challenging course, and the impact on their overall GPA, may seem to indicate that this person is not in fact a high performer. Finally, McNall and Michel (in press) found that proactive personality is negatively related to GPA, which suggests that other factors such as personality may also impact a students GPA adversely. Overall, it is clear that it is the nature of the GPA variable as a 
measure of performance, in terms of factors such as class choice and other factors such as personality that may have a negative impact on GPA.

A sixth, and final limitation of the present study relates to the finding that while hindrance stress was found to be incrementally predictive of individual health and performance/satisfaction outcomes above and beyond challenge stress, the hypotheses which asserted that hindrance stress would be a stronger predictor than challenge stress was not fully supported by the data, especially when considering how highly related challenge and hindrance stress were found to be in this study, with a correlation of .71.

\section{Future Directions}

While this study was able to shed considerable light on the existence of relationships between stress appraisals and individual outcomes, to understand the nature of the relationships between stress appraisals and individual outcomes more fully, researchers should consider evaluating stress based on type and magnitude. As discussed earlier, previous research by Cavanaugh, et al. (2000) and Lepine, et al. (2000), has considered the importance of directionality as it relates to individual outcomes, i.e., positive and negative stress types, however research has not yet considered the implications of the magnitude of a stressor combined with direction of the stressor on the manifestation of individual outcomes. One possible avenue for addressing this gap in the research would be to take a two step approach. The first step would be to develop a stress scale which would assess stress on a continuum starting with low magnitude challenge and going all the way to high level hindrance. Such a scale would afford researchers the opportunity to evaluate stress from the standpoint of both directionality and magnitude and may as a result further develop the concept of stress type. The ability to evaluate 
stress in this way would aid researchers in their analysis of stress as it impacts individuals and organizations and associated outcomes ranging from health to performance to satisfaction.

Additionally researchers may also benefit from a clearer understanding of individual differences, such as current and preexisting health conditions and personality characteristics, and should consider building measurers that could effectively assess factors that may impact participant responses to stress and outcome measures. In other words, if a researcher is able to understand individual contextual factors they may be able to better understand participants' responses to study items. For example, such a study design may consider assigning participants to study conditions designated by personality type, pre-existing anxiety, depression, pre-existing health conditions, determined by prescreening survey items.

Further, researchers may want to consider combining satisfaction and psychological outcomes in an effort to better conceptualize satisfaction as a psychological state. Seligman (1991), in his discussions of positive psychology and learned optimism, has suggested that a positive psychological state is directly related to satisfaction in a given domain. In other words, the psychological state of an individual is partially responsible for determining perceptions of and comfort within the environment and can also contribute to optimal functioning within the environment.

Overall, and in light of these study findings, it may be advisable not to limit the concept of stress to two specific types, that of challenge and hindrance, without first also considering the magnitude of the stressor and the individual differences that may impact appraisal. Future challenge-hindrance stress/outcome research may want to consider one 
of two possibilities. The first possibility is that stress is, in fact, a global construct that can not be simplified into two distinct parts. This possibility is particularly intriguing as the correlation of challenge and hindrance stress is .71 in this study, whereas the correlation between the two, as suggested by Lepine, et al. (2004), was only .40. Thus, as the two stress types appears to be so highly correlated, it seems to raise questions as to how different they truly are, and as a result, how useful as separate measures of stress. Or, alternatively, if stress is to be viewed under the challenge/hindrance lens, it may be important to also consider the characteristics of each individual participant by evaluating any pre-existing physical/mental health factors, pre-participation stress and postparticipation stress levels for the purposes of comparison, challenge and hindrance stress on a continuum, with each defined as consisting of different levels/magnitudes, and finally, individual differences, such as self-esteem, overall academic performance, etc., of individual participants. In light of the above discussion, it seems clear to these researchers that if stress is to be broken down into individual types, two types is by no means sufficient in painting an inclusive picture of this complex construct. 


\section{REFERENCES}

American Psychiatric Association. (2000). Diagnostic and statistical manual of mental disorders (4th ed.). Washington, DC: American Psychiatric Association.

Ashford, S. J., Rothbard, N. P., Piderit, S. K., \& Dutton, J. E. (1998). Out on a limb: The role of context and impression management in selling gender-equity issues. Administrative Science Quarterly, 43, 23-57. doi:10.2307/2393590

Baron, R. M., \& Kenny, D. A. (1986). The moderator- mediator variable distinction in social psychological research: Conceptual, strategic, and statistical considerations. Journal of Personality and Social Psychology, 51, 1173-1182. doi:10.1037/00223514.51.6.1173

Berry, C. M., \& Sackett, P. R. (2009). Individual differences in course choice result in underestimation of the validity of college admissions systems. Psychological Science, 20, 822-830.

Butler, A. B. (2007). Job characteristics and college performance and attitudes: A model of work-school conflict and facilitation. Journal of Applied Psychology, 92, 500510. doi:10.1037/0021-9010.92.2.500

Cannon, W. B. (1932). The Wisdom of the Body. New York, NY: W. W. Norton.

Cavanaugh, M. A., Boswell, W. R., Roehling, M. V., \& Boudreau, J. W. (2000). An empirical examination of self-reported work stress among U.S. managers. Journal of Applied Psychology, 85, 65-74. doi:10.1037/0021-9010.85.1.65

Cohen, S., Kamarck, T., Mermelstein, R. (1983). A global measure of perceived stress. Journal of Health and Social Behavior, 24, 385-396. doi:10.2307/2136404

Collins, L. M., Graham, J. W., \& Flaherty, B. P. (1998). An alternative framework for defining mediation. Multivariate Behavioral Research, 33, 295-312. doi:10.1207/s15327906mbr3302_5

Cronbach, L. J. (1970). Essential of Psychological Testing (3rd Edition). New York: Harper \& Row.

DeLongis, A., Folkman, S., \& Lazarus, R. S. (1988). The Impact of Daily Stress on Health and Mood: Psychological and Social Resources as Mediators. Journal of Personality and Social Psychology, 54, 486-495. doi:10.1037/0022-3514.54.3.486

Dewa, C. S., McDaid, D, \& Ettner, S. L. (in press). An international perspective on worker mental health problems: Who bears the burden and how are costs addressed? Canadian Journal of Psychiatry. 
Folkman, S. (1984). Personal control and stress and coping processes: A theoretical analysis. Journal of Personality and Social Psychology, 46, 839-852. doi:10.1037/0022-3514.46.4.839

Folkman, S. \& Lazarus, R. S. (1986). Stress process and depressive symptomatology. Journal of Abnormal Psychology, 95, 107-113. doi:10.1037/0021-843X.95.2.107

Frone, M. R. (2008). Are work stressors related to employee substance use? The importance of temporal context in assessment of alcohol and illicit drug use. Journal of Applied Psychology, 93, 199-206. doi:10.1037/0021-9010.93.1.199

Ganster, D.C. \& Schaubroeck, J. (1991). Work stress and employee health. Journal of Management, 17, 235-271. doi:10.1177/014920639101700202

Goeders, N. E. (2003). The impact of stress on addiction. European Neuropsychopharmacology, 13, 435-441. doi:10.1016/j.euroneuro.2003.08.004

Haar, J. M. (2006). Challenge and hindrance stressors in New Zealand: Exploring social exchange theory outcomes. The International Journal of Human Resource Management,17, 1942-1950.

Hackman, J. R., \& Oldham, G. R. (1976). Motivation through the design of work: Test of a theory. Organizational Behavior and Human Performance, 16, 250-279. doi:10.1016/0030-5073(76)90016-7

Hogan, T (1991). Personality and personality measurement. In M. D. Dunnette \& L. M. Hough (Eds.), Handbook of industrial and organizational psychology (2nd ed., Vol. 2, pp. 873-919). Palo Alto, CA: Consulting Psychologists Press.

Jex, S. M., Beehr, T. A., \& Roberts, C. K. (1992). The meaning of occupational stress items to survey respondents. Journal of Applied Psychology, 77, 623-628. doi:10.1037/0021-9010.77.5.623

Judd, C. M., \& Kenny, D. A. (198 Ib). Process analysis: Estimating mediation in evaluation research. Evaluation Research, 5, 602-619.

Judge, T. A., Thoresen, C. J., Bono, J. E., \& Patton, G. K. (2001). The job satisfactionJob performance relationship: A qualitative and quantitative review. Psychological Bulletin, 127, 376-407. doi: I0.1037//0033-2909.I27.3.376

Kahn, R.L., Wolfe, D.M., Quinn, R.P., Snoek, J.D., \& Rosenthal, R.A. (1964). Organizational stress: Studies in role conflict and ambiguity, New York: John Wiley \& Sons. 
Kelloway, E.K. \& Barling, J. (1991). Job characteristics, role stress and mental health. Journal of Occupational Psychology, 64, 291-304.

Kenny, D. A., Kashy, D. A., \& Bolger, N. (1998). Data analysis in social psychology. In D. Gilbert, S. T. Fiske, \& G. Lindzey (Eds.), Handbook of social psychology (4th., Vol.1, pp. 233-265). New York: McGraw-Hill.

Klainin, P. (2009). Stress and health outcomes: The mediating role of negative affectivity in female health care workers. International Journal of Stress Management, 16, 45-64. doi:10.1037/a0013693

Lazarus, R.S. (1966). Psychological stress and the coping process. New York: McGrawHill.

Lazarus, R. S. (1981). The stress and coping paradigm. In C. Eisdorfer, D. Cohen, A. Kleinman, \& P. Maxim (Eds.), Models for clinical psychopathology (pp. 177214). New York: Spectrum.

Lazarus, R. S., \& Folkman, S. (1984). Stress, appraisal, and coping. New York: Springer.

Lemyre, L. \& Tessier, R. (2003). Measuring psychological stress: Concept, model, and measurement instrument in primary care research. Canadian Family Physician, 49, 1159-1160.

Lepine, J. A., Lepine, M. A., \& Jackson, C. L. (2004). Challenge and hindrance stress: Relationships with exhaustion, motivation to learn, and learning performance. Journal of Applied Psychology, 89, 883-889. doi:10.1037/0021-9010.89.5.883

Levenson, J. L. (2006). Essentials of psychosomatic medicine. American Psychiatric Press Inc.

Linden, M. \& Muschalla, B. (2007). Anxiety disorders and workplace-related anxieties. Journal of Anxiety Disorders, 21, 467-474. doi:10.1016/j.janxdis.2006.06.006

MacKinnon, D. P. (2000). Contrasts in multiple mediator models. In J. S. Rose, L. Chassin, C. C. Presson, \& S. J. Sherman (Eds.), Multivariate applications in substance use research: New methods for new questions (pp. 141-160). Mahwah, NJ: Erlbaum.

MacKinnon, D. P., Krull, J. L., \& Lockwood, C. M. (2000). Equivalence of the mediation, confounding and suppression effects. Prevention Science, 1, 173-181. doi:10.1023/A:1026595011371

Markel, K. S. \& Frone, M. R. (1998). Job characteristics, work-school conflict, and 
school outcomes among adolescents: Testing a structural model. Journal of Applied Psychology, 83, 277-287. doi:10.1037/0021-9010.83.2.277

Mathieu, J. E. \& Zajac, D. M. (1990). A review and meta-analysis of the antecedents, correlates, and consequences of organizational commitment. Psychological Bulletin, 108, 171-194. doi:10.1037/0033-2909.108.2.171

McNall, L. A., \& Michel, J. S., \& (in press). A dispositional approach to work-school conflict and enrichment. Journal of Business \& Psychology.

Organ, D. W. (1988). A restatement of the satisfaction-performance hypothesis. Journal of Management, 14, 547-557. doi: 10.1177/014920638801400405

Pearsall, M. J., Ellis, A. P. J., \& Stein, J. H. (2009). Coping with challenge and hindrance stressors in teams: Behavioral, cognitive, and affective outcomes. Organizational Behavior and Human Decision Processes, 109, 18-28. doi:10.1016/j.obhdp.2009.02.002

Pedhazur, E. J. (1997). Multiple regression in behavioral research (3rd ed.). Belmont, CA: Wadsworth Publishing.

Raeve, L. D., Kant, I, Jamsem, N. W. H., Vasse, R. M., \& van den Brandt, P. A. (2009). Changes in mental health as a predictor of changes in working time arrangements and occupational mobility: Results from a prospective cohort study. Journal of Psychosomatic Research, 66, 137-145. doi:10.1016/j.jpsychores.2008.05.007

Sanderson, K. \& Andrews, G. (in press). Common mental disorders in the workforce: Recent findings from descriptive and social epidemiology. Canadian Journal of Psychiatry.

Seligman, M. E. P. (1998). Learned optimism: How to change your mind and your life. New York: Free Press.

Selye, H. (1946). The general adaptation syndrome and the diseases of adaptation. Journal of Clinical Endocrinology, 6, 117-230. doi:10.1210/jcem-6-2117

Seyle, H. (1956). The Stress of life. New York: McGraw-Hill.

Shrout, P. E. and Bolger, N. (2002). Mediation in experimental and nonexperimental studies: New procedures and recommendations. Psychological Methods, 7, 422445. doi: $10.1037 / 1082-989 X .7 .4 .422$

Spector, P.E., Dwyer, D.J., \& Jex, S.M. (1988). Relation of job stressors to affective, health, and performance outcomes: A comparison of multiple data sources. 
Journal of Applied Psychology, 73, 11-19. doi:10.1037/0021-9010.73.1.11

Spector, P. E. \& Jex, S. M. (1998). Development of four self-report measures of job stressors and strain: Interpersonal conflict at work scale, organizational constraints scale, quantitative workload inventory, and physical symptoms inventory. Journal of Occupational Health Psychology, 3, 356-367. doi:10.1037/1076-8998.3.4.356

Stansfeld, S. A., Blackmore, E. R., Zagorski, B. M., Munce, S., Stewart, D. E., \& Weller, I. (2008). Work characteristics and social phobia in a nationally representative employed sample. The Canadian Journal of Psychiatry, 53, 371-376.

Watson, D. \& Friend, R. (1969). Measurement of social-evaluative anxiety. Journal of Consulting and Clinical Psychology, 33, 448-457. doi:10.1037/h0027806

Wright, T. A. \& Diamond, W. J. MD (2006). Getting the 'pulse' of your employees: The use of cardiovascular research in better understanding behavior in organizations. Journal of Organizational Behaviour, 27, 395-401. doi:10.1002/job.374 


\section{APPENDIX}

Time 1 Surveys

Please enter your age

Are you currently cohabitating with family:

Yes

No

Are you currently employed:

Yes

No

How many hours per week do you spend on the following tasks:

School tasks

Occupational tasks

Family tasks

Other

Please select your current year of study:

Freshman

Sophomore

Junior

Senior

What is you university enrollment status:

Part Time

Full Time

Please select your ethnicity:

White

Black

Hispanic

Asian

Other

Panther ID (to pull GPA):

Challenge/Hindrance Stress Scale (10 Items)

Lepine, J. A., Lepine, M. A., \& Jackson, C. L. (2004). Challenge and hindrance stress: Relationships with exhaustion, motivation to learn, and learning performance. Journal of Applied Psychology, 89 (5), 883-889.

Please indicate the amount of stress you associate with each of the following items using the 5-point Likert scale provided.

$1=$ Produces no stress

$2=$

$3=$

$4=$ 
$5=$ Produces a great deal of stress

1. The amount of time spent on "busy work" for your classes.

123

45

2. The degree to which favoritism rather than performance affects final grades in your classes.

45

3. The inability to clearly understand what is expected of you in your classes.

45

4. The amount of hassles you need to go through to get projects/assignments done.

45

5. The degree to which your learning progression seems stalled.

45

6 . The number of projects/assignments in your classes.

45

7. The amount of time spent working on projects/assignments for your classes.

$1 \quad 2 \quad 3$ 45

8 . The difficulty of the work required in your classes.

45

9. The volume of coursework that must be completed in your classes. $\quad \begin{array}{lll}2 & 3\end{array}$

45

10. The time pressures experienced for completing work required in your classes. 45

Time 2 Surveys

\section{Physical Symptoms Inventory, PSI (18 Items)}

Spector, P. E., \& Jex, S. M. (1998). Development of Four Self-Report Measures of Job Stressors and Strain: Interpersonal Conflict at Work Scale, Organizational Constraints Scale, Quantitative Workload Inventory, and Physical Symptoms Inventory. Journal of Occupational Health Psychology, 3, 356-367. (All: describes development of the scales.)

During the past 30 days did you have any of the following symptoms?

If you did have the symptom, did you see a doctor about it?

Over the past 6 months, how often have you experienced each of the following symptoms? 
$1=$ Less than once per month or never

$2=$ Once or twice per month

$3=$ Once or twice per week

$4=$ Once or twice per day

$5=$ Several times per day

\begin{tabular}{llllll}
\hline 1. An upset stomach or nausea & 1 & 2 & 3 & 4 & 5
\end{tabular}

\begin{tabular}{llllll}
\hline 2. A backache & 1 & 2 & 3 & 4 & 5
\end{tabular}

\begin{tabular}{llllll}
\hline 3. Trouble sleeping & 1 & 2 & 3 & 4 & 5
\end{tabular}

\begin{tabular}{llllll}
\hline 4. A skin rash & 1 & 2 & 3 & 4 & 5
\end{tabular}

\begin{tabular}{llllll}
\hline 5. Shortness of breath & 1 & 2 & 3 & 4 & 5
\end{tabular}

\begin{tabular}{llllll}
\hline 6. Chest pain & 1 & 2 & 3 & 4 & 5
\end{tabular}

\begin{tabular}{llllll}
\hline 7. Headache & 1 & 2 & 3 & 4 & 5
\end{tabular}

\begin{tabular}{llllll}
\hline 8. Fever & 1 & 2 & 3 & 4 & 5
\end{tabular}

\begin{tabular}{llllll}
\hline 9. Acid indigestion or heartburn & 1 & 2 & 3 & 4 & 5
\end{tabular}

\begin{tabular}{llllll}
\hline 10. Eye strain & 1 & 2 & 3 & 4 & 5
\end{tabular}

\begin{tabular}{llllll}
\hline 11. Diarrhea & 1 & 2 & 3 & 4 & 5
\end{tabular}

12. Stomach cramps (Not menstrual)

$\begin{array}{lllll}1 & 2 & 3 & 4 & 5\end{array}$

\begin{tabular}{llllll}
\hline 13. Constipation & 1 & 2 & 3 & 4 & 5
\end{tabular}

14. Heart pounding when not exercising

$\begin{array}{lllll}1 & 2 & 3 & 4 & 5\end{array}$

\begin{tabular}{llllll}
\hline 15. An infection & 1 & 2 & 3 & 4 & 5
\end{tabular}

\begin{tabular}{llllll}
\hline 16. Loss of appetite & 1 & 2 & 3 & 4 & 5
\end{tabular}

\begin{tabular}{llllll}
\hline 17. Dizziness & 1 & 2 & 3 & 4 & 5
\end{tabular}

\begin{tabular}{llllll}
\hline 18. Tiredness or fatigue & 1 & 2 & 3 & 4 & 5
\end{tabular} 


\section{$\underline{\text { Social Avoidance and Distress Scale (SADS) (28 Items) }}$}

Watson, D. \& Friend, F. (1969). Measurement of socially-evaluative anxiety. Journal of Consulting and Clinical Psychology, 33, 448-457.

The statements below inquire about your personal reactions to a variety of situations. Consider each statement carefully. Then indicate whether the statement is true or false with regard to your typical behavior.

1. I feel relaxed even in unfamiliar social situations.

2. I try to avoid situations which force me to be sociable.

3. It is easy for me to relax when I am with strangers.

4. I have no particular desire to avoid people.

5. I often find social occasions upsetting.

6. I usually feel calm and comfortable at social occasions.

7. I am usually at ease when talking to someone of the opposite sex.

8. I try to avoid talking to people unless I know them well.

9. If the chance comes to meet new people, I often take it.

10. I often feel nervous or tense in casual get-togethers in which both sexes are present.

11. I am usually nervous with people unless I know them well.

12. I usually feel relaxed when I am with a group of people.

13. I often want to get away from people.

14. I usually feel uncomfortable when I am in a group of people I don't know.

15. I usually feel relaxed when I meet someone for the first time. 
16. Being introduced to people makes me tense and nervous.

17. Even though a room is full of strangers, I may enter it anyway.

18. I would avoid walking up and joining a large group of people.

19. When my superiors want to talk with me, I talk willingly.

20. I often feel on edge when I am with a group of people.

21. I tend to withdraw from people.

22. I don't mind talking to people at parties or social gatherings.

23. I am seldom at ease in a large group of people.

24. I often think up excuses in order to avoid social engagements.

25. I sometimes take the responsibility for introducing people to each other.

26. I try to avoid formal social occasions.

27. I usually go to whatever social engagements I have.

28. I find it easy to relax with other people.

\section{$\underline{\text { School Satisfaction Scale (6 Items) }}$}

Butler, A. B. (2007). Job characteristics and college performance and attitudes: A model of work-school conflict and facilitation. Journal of Applied Psychology, 92, 500-510.

Instructions: Below are several statements about you with which you may agree or disagree. Using the response scale below, indicate your agreement or disagreement with each item by placing the appropriate number on the line preceding that item.

$1=$ Strongly Disagree

$2=$ Disagree

$3=$ Neutral

$4=$ Agree 
$5=$ Strongly Agree

1. I enjoy being a student on this campus.

$\begin{array}{lllll}1 & 2 & 3 & 4 & 5\end{array}$

2. This university meets my expectations.

$\begin{array}{lllll}1 & 2 & 3 & 4 & 5\end{array}$

3. I feel comfortable at this university.

$\begin{array}{lllll}1 & 2 & 3 & 4 & 5\end{array}$

4. I am satisfied with my education at this university.

$\begin{array}{lllll}1 & 2 & 3 & 4 & 5\end{array}$

5. I am pleased with the services I received at this university.

$\begin{array}{lllll}1 & 2 & 3 & 4 & 5\end{array}$

6. Overall, I am satisfied with my experience at this university.

\section{$\underline{\text { School Performance (4 Items) }}$}

Markel, K. S., \& Frone, M. R. (1998). Job characteristics, work-school conflict, and school outcomes among adolescents: Testing a structural model. Journal of Applied Psychology, 83, 277-287.

During the past school year, how often have you done each of the following things?

For each question choose from the following alternatives:

$$
\begin{aligned}
& 1=\text { never } \\
& 2=\text { almost never } \\
& 3=\text { sometimes } \\
& 4=\text { fairly often } \\
& 5=\text { very often }
\end{aligned}
$$

1. Put forth a high level of effort in class. 5

2. Completed assignments on time. 45

3. Skipped a whole day of school without a real excuse (reverse scored). $\quad \begin{array}{llll}1 & 2 & 3 & 4\end{array}$ 5

4. Cut classes, but not a whole day of school (reverse scored).

$\begin{array}{llll}1 & 2 & 3 & 4\end{array}$ 5

\section{Challenge/Hindrance Stress Scale (10 Items)}

Lepine, J. A., Lepine, M. A., \& Jackson, C. L. (2004). Challenge and hindrance stress: Relationships with exhaustion, motivation to learn, and learning performance. Journal of Applied Psychology, 89 (5), 883-889.

Please indicate the amount of stress you associate with each of the following items using the 5-point Likert scale provided.

$1=$ Produces no stress

$2=$

$3=$ 
$4=$

$5=$ Produces a great deal of stress

1. The amount of time spent on "busy work" for your classes.

$\begin{array}{lll}1 & 2 & 3\end{array}$

45

2. The degree to which favoritism rather than performance affects final grades in your classes.

123

45

3. The inability to clearly understand what is expected of you in your classes.

45

4. The amount of hassles you need to go through to get projects/assignments done.

45

5. The degree to which your learning progression seems stalled.

123

45

6. The number of projects/assignments in your classes.

$1 \quad 2 \quad 3$

45

7. The amount of time spent working on projects/assignments for your classes.

45

8. The difficulty of the work required in your classes.

45

9. The volume of coursework that must be completed in your classes.

45

10. The time pressures experienced for completing work required in your classes.

123 45 


\begin{tabular}{|c|c|}
\hline Hypothesis 1a & $\begin{array}{l}\text { Challenge stress will be positively related to physiological health } \\
\text { outcomes (IV=Challenge Stress; DV=PSI). }\end{array}$ \\
\hline Hypotheses $1 \mathrm{~b}$ & $\begin{array}{l}\text { Hindrance stress will be positively related to physiological health } \\
\text { outcomes (IV=Hindrance Stress; DV=PSI). }\end{array}$ \\
\hline Hypotheses 1c & $\begin{array}{l}\text { Hindrance stress is more strongly related to physiological } \\
\text { outcomes than challenge stress. }\end{array}$ \\
\hline Hypotheses 2a & $\begin{array}{l}\text { Challenge stress will be positively related to psychological health } \\
\text { outcomes (IV=Challenge Stress; DV=SADS). }\end{array}$ \\
\hline Hypotheses 2b & $\begin{array}{l}\text { Hindrance stress will be positively related to psychological health } \\
\text { outcomes (IV=Hindrance Stress; DV=SADS). }\end{array}$ \\
\hline Hypotheses 2c & $\begin{array}{l}\text { Hindrance stress is more strongly related to psychological } \\
\text { outcomes than challenge stress. }\end{array}$ \\
\hline Hypotheses 3a & $\begin{array}{l}\text { Challenge stress will be positively related to school performance } \\
\text { outcomes (IV: Challenge Stress; DV: School Performance). }\end{array}$ \\
\hline Hypotheses 3b & $\begin{array}{l}\text { Hindrance stress will be negatively related to school performance } \\
\text { outcomes (IV: Hindrance Stress; DV: School Performance). }\end{array}$ \\
\hline Hypotheses 3c & $\begin{array}{l}\text { Challenge stress will be positively related to school satisfaction } \\
\text { outcomes (IV: Challenge Stress; DV: School Satisfaction). }\end{array}$ \\
\hline Hypotheses 3d & $\begin{array}{l}\text { Hindrance stress will be negatively related to school satisfaction } \\
\text { outcomes (IV: Hindrance Stress; DV: School Satisfaction). }\end{array}$ \\
\hline Hypotheses 3e & $\begin{array}{l}\text { Hindrance Stress is more strongly related to performance outcomes } \\
\text { than challenge stress. }\end{array}$ \\
\hline Hypotheses $3 \mathrm{f}$ & $\begin{array}{l}\text { Hindrance Stress is more strongly related to satisfaction outcomes } \\
\text { than challenge stress. }\end{array}$ \\
\hline Hypotheses 4 & $\begin{array}{l}\text { The relationship between challenge/hindrance stress appraisal and } \\
\text { performance/satisfaction outcomes is mediated by both } \\
\text { physiological and psychological health. }\end{array}$ \\
\hline
\end{tabular}


Sample size, Descriptive Statistics, Correlations, and Reliabilities of Study Variables

\begin{tabular}{lllllllllll}
\hline Variables & $\mathrm{n}$ & $\mathrm{M}$ & $\mathrm{SD}$ & 1 & 2 & 3 & 4 & 5 & 6 & 7
\end{tabular}

Time 1

$\begin{array}{lllll}\text { 1. Challenge } & 538 & 3.51 & .99 & .94\end{array}$

Stress

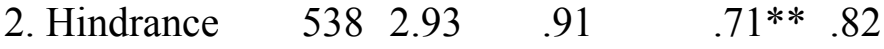

Stress

Time 2

3. School

$\begin{array}{llllll}538 & 4.05 & .64 & .09 * & .01 & .71\end{array}$

Performance

4. School

$538 \quad 3.90$

.76

Satisfaction

5. Physiological $538 \quad 1.68 \quad .46 \quad .18^{* *} .26^{* *}-.12^{* *} .20^{* *} .85$

Health

6. Psychological 5387.73

$6.76 \quad .18^{* *} .22 * *-.06 \quad-.13^{* *} .27 * * .92$

Health

7. GPA

1842.90

1.04

$.05 \quad-.07$

$.011-.09$

$.01 \quad-.02 \quad-$

Note. ${ }^{*} p<.05{ }^{* *} p<.01$ 
Correlations and t-values with Challenge and Hindrance Stress Predictors (Hypotheses $1 c, 2 c, 3 e, 3 f)$

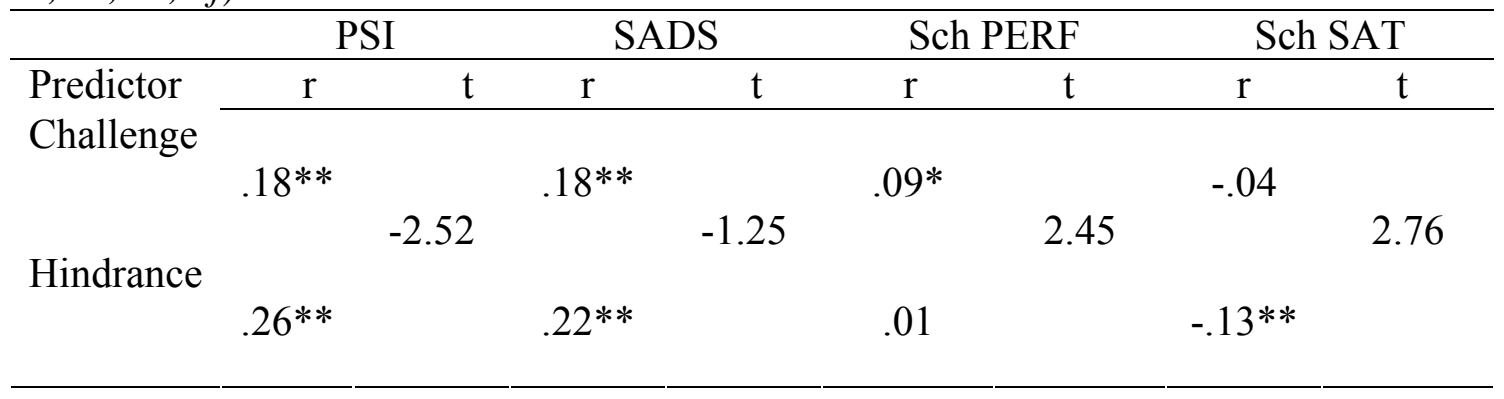

Note. ${ }^{*} p<.05 * * p<.01$ 
Confidence Intervals with Challenge and Hindrance Stress Predictors (Hypotheses 1c, 2c, $3 e, 3 f)$

\begin{tabular}{|c|c|c|c|c|c|c|c|c|c|c|}
\hline \multirow{3}{*}{ Predictor } & \multicolumn{2}{|c|}{ PSI } & \multicolumn{2}{|c|}{ SADS } & \multicolumn{2}{|c|}{ School PERF } & \multicolumn{2}{|c|}{ School SAT } & \multicolumn{2}{|c|}{ GPA } \\
\hline & \multicolumn{2}{|c|}{$95 \%$ CI } & \multicolumn{2}{|c|}{$95 \%$ CI } & \multicolumn{2}{|c|}{$95 \%$ CI } & \multicolumn{2}{|c|}{$95 \%$ CI } & \multicolumn{2}{|c|}{$95 \%$ CI } \\
\hline & Lower & Upper & Lower & Upper & Lower & Upper & Lower & Upper & Lower & Upper \\
\hline $\begin{array}{l}\text { Challenge } \\
\text { Stress }\end{array}$ & 0.10 & 0.27 & 0.10 & 0.27 & 0.01 & 0.17 & -0.12 & 0.04 & -0.10 & 0.20 \\
\hline $\begin{array}{l}\text { Hindrance } \\
\text { Stress }\end{array}$ & 0.18 & 0.34 & 0.14 & 0.31 & -0.07 & 0.09 & -0.22 & -0.05 & -0.22 & 0.08 \\
\hline \multirow[b]{2}{*}{ Predictor } & \multicolumn{2}{|c|}{$90 \%$ CI } & \multicolumn{2}{|c|}{$90 \%$ CI } & \multicolumn{2}{|c|}{$90 \%$ CI } & \multicolumn{2}{|c|}{$90 \%$ CI } & \multicolumn{2}{|c|}{$90 \%$ CI } \\
\hline & Lower & Upper & Lower & Upper & Lower & Upper & Lower & Upper & Lower & Upper \\
\hline $\begin{array}{l}\text { Challenge } \\
\text { Stress }\end{array}$ & 0.01 & 0.05 & 0.01 & 0.11 & -0.01 & 0.02 & 0.00 & 0.01 & -0.01 & 0.01 \\
\hline $\begin{array}{l}\text { Hindrance } \\
\text { Stress }\end{array}$ & 0.04 & 0.11 & 0.02 & 0.08 & 0.00 & 0.01 & 0.00 & 0.04 & -0.01 & 0.02 \\
\hline
\end{tabular}


Steps to Test for Mediation (Hypothesis 4)

\begin{tabular}{|c|c|c|c|c|c|c|c|c|}
\hline $\begin{array}{l}\text { Step 1: IV predicts } \\
\text { DV }\end{array}$ & \multicolumn{2}{|c|}{$\begin{array}{l}\text { IV: } \\
\text { Challenge } \\
\text { Stress } \\
\end{array}$} & \multicolumn{2}{|c|}{$\begin{array}{l}\text { IV: } \\
\text { Hindrance } \\
\text { Stress }\end{array}$} & \multicolumn{2}{|c|}{$\begin{array}{l}\text { IV: } \\
\text { Challenge } \\
\text { Stress }\end{array}$} & \multicolumn{2}{|c|}{$\begin{array}{l}\text { IV: } \\
\text { Hindrance } \\
\text { Stress }\end{array}$} \\
\hline Regression 1 & \multicolumn{2}{|c|}{$\begin{array}{l}\text { DV: } \\
\text { Performance }\end{array}$} & \multicolumn{2}{|c|}{$\begin{array}{l}\text { DV: } \\
\text { Performance }\end{array}$} & \multicolumn{2}{|c|}{$\begin{array}{l}\text { DV: } \\
\text { Satisfaction }\end{array}$} & \multicolumn{2}{|c|}{$\begin{array}{l}\text { DV: } \\
\text { Satisfaction }\end{array}$} \\
\hline $\begin{array}{l}\text { Step 2: } \\
\text { IV predicts mediator }\end{array}$ & \multicolumn{2}{|c|}{$\begin{array}{l}\text { IV: } \\
\text { Challenge } \\
\text { Stress }\end{array}$} & \multicolumn{2}{|c|}{$\begin{array}{l}\text { IV: } \\
\text { Hindrance } \\
\text { Stress }\end{array}$} & \multicolumn{2}{|c|}{$\begin{array}{l}\text { IV: } \\
\text { Challenge } \\
\text { Stress }\end{array}$} & \multicolumn{2}{|c|}{$\begin{array}{l}\text { IV: } \\
\text { Hindrance } \\
\text { Stress }\end{array}$} \\
\hline Regression 2 & \multicolumn{2}{|c|}{ DV: PSI } & \multicolumn{2}{|c|}{ DV: PSI } & \multicolumn{2}{|c|}{ DV: SADS } & \multicolumn{2}{|c|}{ DV: SADS } \\
\hline $\begin{array}{l}\text { Step 3: } \\
\text { When a mediating } \\
\text { variable is present, the } \\
\text { relationship between } \\
\text { the variables in step 1 } \\
\text { (C-P; H-P; C-S; H-S) } \\
\text { must be reduced } \\
\text { (partial mediation) or } \\
\text { eliminated (full } \\
\text { mediation) }\end{array}$ & $\begin{array}{l}\text { IV: } \\
\text { C- } \\
\text { Stress } \\
\\
\text { Med: } \\
\text { PSI }\end{array}$ & \begin{tabular}{|l} 
IV: \\
C- \\
Stress \\
Med: \\
SADS
\end{tabular} & \begin{tabular}{|l} 
IV: \\
H- \\
Stress \\
Med: \\
PSI
\end{tabular} & \begin{tabular}{|l} 
IV: \\
H- \\
Stress \\
Med: \\
SADS
\end{tabular} & $\begin{array}{l}\text { IV: } \\
\text { C- } \\
\text { Stress } \\
\text { Med: } \\
\text { PSI }\end{array}$ & $\begin{array}{l}\text { IV: } \\
\text { C- } \\
\text { Stress } \\
\text { Med: } \\
\text { SADS }\end{array}$ & \begin{tabular}{|l} 
IV: \\
H- \\
Stress \\
Med: \\
PSI
\end{tabular} & $\begin{array}{l}\text { IV: } \\
\text { H- } \\
\text { Stress } \\
\text { Med: } \\
\text { SADS }\end{array}$ \\
\hline Regression 3 & \multicolumn{2}{|c|}{$\begin{array}{l}\text { DV: } \\
\text { Performance }\end{array}$} & \multicolumn{2}{|c|}{$\begin{array}{l}\text { DV: } \\
\text { Performance }\end{array}$} & \multicolumn{2}{|c|}{$\begin{array}{l}\text { DV: } \\
\text { Satisfaction }\end{array}$} & \multicolumn{2}{|c|}{$\begin{array}{l}\text { DV: } \\
\text { Satisfaction }\end{array}$} \\
\hline
\end{tabular}

$\mathrm{IV}=$ Independent Variable

DV=Dependent Variable

Med-Mediator

$\mathrm{C}=$ Challenge; $\mathrm{H}=$ Hindrance

$\mathrm{P}=$ Performance; $\mathrm{S}=$ Satisfaction 
Mediated Regression Analyses for Challenge and Hindrance Stress on Performance, with Health as the Mediator (Hypothesis 4)

\begin{tabular}{|c|c|c|c|c|c|c|c|}
\hline & \multirow[t]{2}{*}{ Performance } & \multirow[t]{2}{*}{ PSI } & \multirow[t]{2}{*}{ SADS } & \multicolumn{2}{|c|}{ Performance } & \multicolumn{2}{|c|}{ Performance } \\
\hline & & & & Step 1 & Step 2 & Step 1 & Step 2 \\
\hline Challenge Stress & $.09 *$ & $.18^{* * *}$ & $.18 * * *$ & $.09 *$ & $.11^{* *}$ & $.09 *$ & $.1 * *$ \\
\hline PSI & & & & & $-.14 * * *$ & & \\
\hline SADS & & & & & & & -.07 \\
\hline $\mathrm{R}^{2}$ & $.01 *$ & $.03 * * *$ & $.03 * * *$ & $.01 *$ & $.03 * * *$ & $.01 *$ & $.01 *$ \\
\hline$\Delta \mathrm{R}^{2}$ & $.01 *$ & $.03 * * *$ & $.03 * * *$ & $.01 *$ & $.02 * * *$ & $.01 *$ & $.00 *$ \\
\hline Hindrance Stress & .01 & $.26 * * *$ & $.22 * * *$ & .01 & .05 & .01 & .03 \\
\hline PSI & & & & & $-.14 * *$ & & \\
\hline SADS & & & & & & & -.06 \\
\hline $\mathrm{R}^{2}$ & .00 & $.07 * * *$ & $.05 * * *$ & .00 & $.02 * *$ & .00 & .00 \\
\hline$\Delta \mathrm{R}^{2}$ & .00 & $.07 * * *$ & $.05 * * *$ & .00 & $.02 * *$ & .00 & .00 \\
\hline
\end{tabular}

Note. ${ }^{*} p<.05 * * p<.01 * * * p<.001$, PSI $=$ Physiological Health, SADS = Psychological Health 
Mediated Regression Analyses for Challenge and Hindrance Stress on Satisfaction, with Health as the Mediator (Hypothesis 4)

\begin{tabular}{|c|c|c|c|c|c|c|c|}
\hline \multirow{3}{*}{ 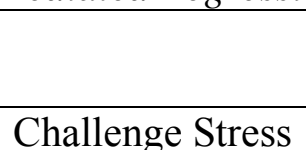 } & \multirow[t]{2}{*}{ Satisfaction } & \multirow[t]{2}{*}{ PSI } & \multirow[t]{2}{*}{ SADS } & \multicolumn{2}{|c|}{ Satisfaction } & \multicolumn{2}{|c|}{ Satisfaction } \\
\hline & & & & Step 1 & Step 2 & Step 1 & Step 2 \\
\hline & -.04 & $.18 * * *$ & $.18 * * *$ & -.04 & -.02 & -.04 & -.02 \\
\hline PSI & & & & & $-.13 * *$ & & \\
\hline SADS & & & & & & & $-.13 * *$ \\
\hline $\mathrm{R}^{2}$ & .00 & $.03 * * *$ & $.03 * * *$ & .00 & $.02 * *$ & .00 & $.02 * *$ \\
\hline$\Delta \mathrm{R}^{2}$ & .00 & $.03 * * *$ & $.03 * * *$ & .00 & $.02 * *$ & .00 & $.02 * *$ \\
\hline Hindrance Stress & $-.13 * *$ & $.26 * * *$ & $.22 * * *$ & $-.13 * *$ & $-.10^{*}$ & $-.13 * *$ & $-.10 *$ \\
\hline PSI & & & & & $-.11 *$ & & \\
\hline SADS & & & & & & & $-.11 *$ \\
\hline $\mathrm{R}^{2}$ & $.02 * *$ & $.07 * * *$ & $.05^{* * *}$ & $.02 * *$ & $.03 * * *$ & $.02 * *$ & $.03 * * *$ \\
\hline$\Delta \mathrm{R}^{2}$ & $.02 * *$ & $.07 * * *$ & $.05 * * *$ & $.02 * *$ & $.01 * * *$ & $.02 * *$ & $.01 * * *$ \\
\hline
\end{tabular}

Note. ${ }^{*} p<.05 * * p<.01 * * * p<.001$, PSI $=$ Physiological Health, SADS = Psychological Health 